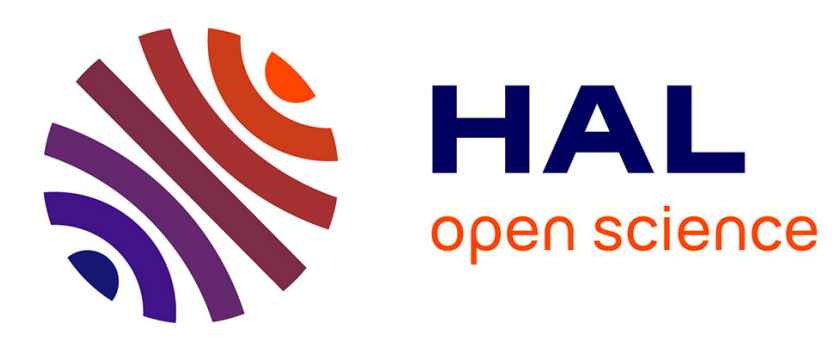

\title{
Reduction of Long-Term Bedrock Incision Efficiency by Short-Term Alluvial Cover Intermittency
}

Dimitri Lague

\section{To cite this version:}

Dimitri Lague. Reduction of Long-Term Bedrock Incision Efficiency by Short-Term Alluvial Cover Intermittency. Journal of Geophysical Research: Earth Surface, 2010, 115 (F2), pp.F02011. 10.1029/2008JF001210 . insu-00609622

\section{HAL Id: insu-00609622 \\ https://hal-insu.archives-ouvertes.fr/insu-00609622}

Submitted on 1 Apr 2016

HAL is a multi-disciplinary open access archive for the deposit and dissemination of scientific research documents, whether they are published or not. The documents may come from teaching and research institutions in France or abroad, or from public or private research centers.
L'archive ouverte pluridisciplinaire HAL, est destinée au dépôt et à la diffusion de documents scientifiques de niveau recherche, publiés ou non, émanant des établissements d'enseignement et de recherche français ou étrangers, des laboratoires publics ou privés. 


\title{
Reduction of long-term bedrock incision efficiency by short-term alluvial cover intermittency
}

\author{
D. Lague ${ }^{1}$ \\ Received 24 November 2008; revised 5 November 2009; accepted 1 December 2009; published 4 May 2010.
}

[1] Fluctuations of the sediment volume stored in mountain channels are driven by stochastic variations of discharge and sediment supply and can inhibit bedrock incision if sediment thickness is too large. Here, I study how this short-term stochasticity propagates into the long-term reduction of bedrock incision efficiency (the cover effect) at geological time scales. I introduce a new numerical model that resolves sediment transport and bedrock incision at daily time scales, and is run for thousands of years. It incorporates (1) a transport threshold and daily stochastic variations in water discharge and sediment supply, (2) a freely evolving channel width and slope, and (3) an explicit treatment of alluvial thickness variations and corresponding bed incision reduction. For typical mountain river conditions the model predicts that alluvial cover oscillates between complete and negligible incision reduction. In this intermittent regime the long-term cover effect is mainly set by the fraction of time spent in full cover, and the present-day extent of alluvial cover is not representative of long-term dynamics. The long-term integrated cover effect law differs strongly from proposed theoretical and experimental models, and it is controlled by sediment supply stochasticity rather than the details of cover development at the hydraulic time scale. Model results also suggest that steady state channel configuration always depends on sediment supply rate, while being never limited by transport capacity or strictly detachment limited. These results point out that discharge and sediment supply stochasticity should not be considered less important than the intricate details of incision laws to model long-term bedrock channel dynamics.

Citation: Lague, D. (2010), Reduction of long-term bedrock incision efficiency by short-term alluvial cover intermittency, J. Geophys. Res., 115, F02011, doi:10.1029/2008JF001210.

\section{Introduction}

[2] Rapid mountain river incision through bedrock is an inherently stochastic process resulting from the long-term summation of flow and sediment discharge events at highly variable rates and frequency [Hartshorn et al., 2002; Howard, 1998; Turowski et al., 2008b]. While the actual incision processes remain difficult to apprehend in situ and are the subject of ongoing research [Hancock et al., 1998; Hartshorn et al., 2002; Lamb et al., 2008; Sklar and Dietrich, 2004; Turowski et al., 2007], there is no ambiguity on the inhibiting effect of a thick alluvial cover (several meters) on bed incision. An extreme case is the damming by large landslides or debris flows that reduces the downstream supply of coarse sediment and locally inhibits bedrock incision for several days to years [Benda and Dunne, 1997a; Korup et al., 2006; Lancaster and Grant, 2006; Ouimet et al., 2007]. More commonly, in rapidly eroding areas, the thickness of sediment stored in bedrock channels is known to vary from daily to

\footnotetext{
${ }^{1}$ Géosciences Rennes, Université Rennes 1, UMR 6118, CNRS, Rennes, France.

Copyright 2010 by the American Geophysical Union. 0148-0227/10/2008JF001210
}

yearly time scales [Schuerch et al., 2006; Turowski et al., 2008b]. For instance, in Taiwan, typhoon Longwang (October 2006 , return time $\sim 30-50$ years) deposited up to $8 \mathrm{~m}$ of sediment during a 3 day flood in the Liwu river, whose shortterm averaged incision rate is of the order of $5 \mathrm{~mm} / \mathrm{yr}$ (Figure 1) [Hartshorn et al., 2002; Turowski et al., 2008b]. Bed incision was likely completely inhibited for several months, while subsequent lower flow events were progressively removing the in-channel stored sediment at high rate: only 1-2 m of sediment were protecting the lowest part of the channel 5 months after the typhoon (Figure 1). This example illustrates one of the models postulated by Howard [1998] for the long-term dynamics of mixed bedrock-alluvial channels (channels with a moderate exposure of bedrock and significant alluvial cover deposits elsewhere). It underlines two important aspects of short-term alluvial cover dynamics in bedrock channels [Benda, 1990; Hartshorn et al., 2002; Hovius et al., 2000; Turowski et al., 2008b]: (1) alluvial cover thickness can vary extremely rapidly in steep mountain rivers, and (2) channel bed incision can be negligible during large flood events. How these short-term dynamics propagate through time into long-term inhibition of bed incision is not clearly understood. This is the central question addressed in this paper. In the next paragraphs I detail the elementary 


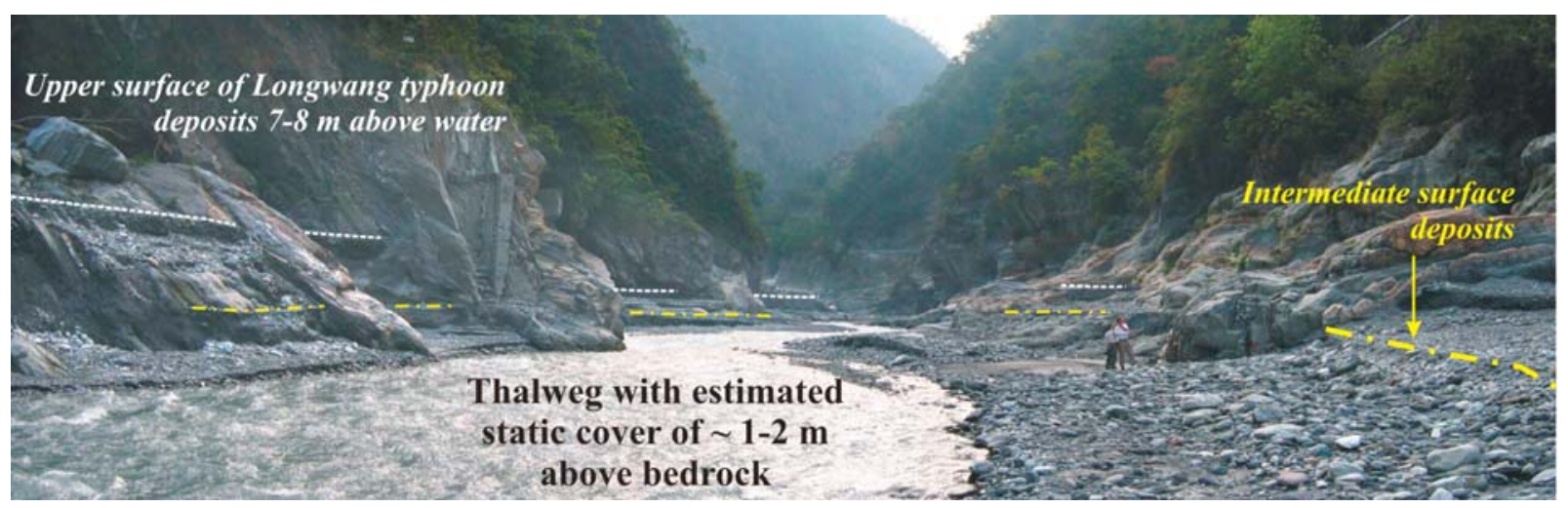

Figure 1. Panorama of the Liwu river in Taiwan, at the Lushui gauging station (March 2006), 5 months after typhoon Longwang deposited up to $8 \mathrm{~m}$ of sediment in a three day flood event (October 2005). Within 5 months, the river has already removed a large part of the deposited sediment during subsequent under capacity discharge events. Intermediate surface deposits (short-term fill terraces) are visible at different elevations below the upper surface. They likely correspond to subsequent discharge events evacuating upstream stored alluvial cover during which local aggradation or net transport might have occurred, but no actual cover degradation. An approximate 1-2 $\mathrm{m}$ alluvial cover is still protecting the bed from incision during low flow events at the time the picture was taken. Note that channel banks are free from cover.

mechanisms and couplings governing bedrock channel evolution that are likely relevant to this problem.

[3] The fluctuations of the volume of sediment deposited in channels over short to intermediate time scales are tied to the relationship between (1) the transport capacity of the channel set by the combination of discharge characteristics (mean, variability) and channel geometry (slope, width, cross section, roughness, grain size distribution, ...) and (2) the frequency-magnitude distribution of sediment supply events to the channel [Benda and Dunne, 1997a; Hovius et al., 2000]. Over geological time scales, bedrock channels are forced to incise to follow relative base-level fall. To do so, their long-term transport capacity $\bar{Q}_{t}$ must be on average larger than or equal to the long-term flux of sediment supply $\bar{Q}_{s}$ over all grain size classes. Erosion and transport processes driving river geometrical change (slope and width) are expected to operate in order to bring the channel into a steady state configuration allowing long-term bedrock incision and sediment transport to operate at the rates imposed by baselevel fall and upstream sediment supply.

[4] However, we still lack a proper understanding of the role played in channel dynamics by short-term fluctuations in alluvial cover and incision. Recent theoretical work has demonstrated that the simple inclusion of a transport threshold to initiate incision combined with stochastic variations of daily discharge results in strongly nonlinear relationships between steady state slope and incision rate compared to the predictions arising from models without daily fluctuations [Lague et al., 2005; Snyder et al., 2003; Tucker and Bras, 2000]. Yet, these studies did not factor in two potentially important factors: (1) the inhibiting effect of daily variation of alluvial cover thickness and (2) the potential variation of channel width with incision rate and sediment supply. This latter effect has been document in the field [Duvall et al., 2004; Lavé and Avouac, 2001; Whittaker et al., 2007] and experimentally [Finnegan et al., 2007; Johnson and Whipple,
2007; Turowski et al., 2006]. It has motivated the development of analytical [Turowski et al., 2007] and numerical models [Stark, 2006; Turowski et al., 2009; Wobus et al., 2006] of channel width evolution and steady state geometry. These models show that channel width dynamics result from the competition between vertical bed incision (narrowing tendency) and lateral bank incision (widening tendency) [Stark, 2006; Turowski et al., 2009; Wobus et al., 2006]. Present-day measurement of erosion distribution in the Liwu river [Hartshorn et al., 2002; Turowski et al., 2008b] shows that bank erosion rates were higher than bed erosion rates during major flood events (return time of 10 and more years). Turowski et al. [2008b] showed that the variation of shear stress distribution with discharge cannot explain this distribution. They concluded that bed incision reduction by an alluvial cover developing at high discharges is dominantly governing the ratio between bed and bank incision rates. Consequently, it is expected that the temporal fluctuations of static alluvial cover on the bed will have a significant impact on channel width evolution. Whether and how this short-term complexity can be averaged out over long time scales is a fundamental question that has not yet been addressed by theoretical work.

[5] Channel width is also an important factor controlling the space available to store sediment, and consequently the long-term incision efficiency reduction. In agreement with this, a theoretical analysis using a constant discharge model and assuming that steady state channel geometry minimizes potential energy, predicts an increase of steady state bedrock channel width with sediment supply rate [Turowski et al., 2007, 2009]. A similar result has been predicted for the relationship between valley width and sediment supply rate in debris flow dominated environments [Lancaster, 2008]. Although it pertains to a slightly different environment than narrow rivers for which the channel/valley width ratio is about one for the mean annual discharge (Figure 1), and 
does not factor in the variability of discharge, it underlines the importance of channel width variations in accommodating various rates of sediment supply.

[6] In modeling studies, the inhibiting effect related to sediment transport is called the cover effect $C_{v}$. It varies between 0 (no incision) and 1 (no cover), and is always expressed as a function of the ratio between flux of sediment supply to the channel and sediment transport capacity $Q_{s} / Q_{t}$. Note that as discharge and sediment variability have never been explicitly accounted for in any previous work, longterm $\bar{Q}_{s} / \bar{Q}_{t}$ and daily equivalent $Q_{s} / Q_{t}$ have been treated as equal. Many ad hoc models dedicated to long-term channel dynamics lump the details of temporal- and reach-scale spatial variations of alluvial cover assuming that the longterm cover effect $\bar{C}_{v}$ decreases linearly with $\bar{Q}_{s} / \bar{Q}_{t}$ [Beaumont et al., 1992; Gasparini et al., 2006; Sklar and Dietrich, 1998; Tucker and Slingerland, 1994]:

$\bar{C}_{v}=1-\frac{\bar{Q}_{s}}{\bar{Q}_{t}}$, for $\bar{Q}_{s} \leq \bar{Q}_{t}$, and $\bar{C}_{v}=0$, for $\bar{Q}_{s}>\bar{Q}_{t}$.

Two other theoretical models developed at the flood time scale invoke more specific effects: (1) in the linear decline model [Sklar and Dietrich, 2004] the development of patches of sediment progressively covering the bed leads to equation (1) (except that it is expressed with daily variable $Q_{s} / Q_{t}$ ), and (2) in the exponential decline model [Turowski et al., 2007] the development of alluvial patches and the increase of near bed sediment concentration increases grain-grain collisions to the detriment of grain-bed impacts. A probabilistic argument shows that in that case

$$
C_{v}=\exp \left(-v \frac{Q_{s}}{Q_{t}}\right)
$$

where $v$ is a cover factor dependent on bed topography and equal to one for a flat bed [Turowski et al., 2007]. In the exponential model, bed incision is never strictly speaking completely inhibited, even if $Q_{s}>Q_{t}$. This arises from the assumption that, starting from a bare bedrock configuration, immobile patches of sediment protecting the bed only develop theoretically once $Q_{s}>Q_{t}$. It leads to the theoretical distinction between a static cover effect (immobile patches of sediment) and a dynamic cover effect (related to the increase of near bed sediment concentration reducing grain-bed impacts and/or mobile patches of sediment) [Turowski et al., 2007]. Experimental results show that for a constant supply of sediment, the fraction of bed covered by immobile patches of sediment increases with $Q_{s} / Q_{t}$ [Chatanantavet and Parker, 2008], and a linear or exponential decay could equally fit the data [Turowski, 2009]. Yet, in natural systems, the alluvial cover thickness in a bedrock channel is not only a function of the instantaneous value of $Q_{s} / Q_{t}$, but also strongly dependent on past history of sediment deposition (Figure 1). This led various authors to postulate a cover effect as a function of the thickness of sediment deposited on the bed [Hancock and Anderson, 2002; Howard, 1998; Stark et al., 2009]. The prerequisite (or consequence) to use $Q_{s} / Q_{t}$-dependent cover models for long-term dynamics is to assume either (1) that $Q_{s} /$ $Q_{t}<1$ for all discharge events or (2) that the long-term integrated effect of alluvial cover variability $\bar{C}_{v}=f\left(\bar{Q}_{s} / \bar{Q}_{t}\right)$ is captured by the same functional relationship as the short-term relationship $C_{v}=f\left(Q_{s} / Q_{t}\right)$. The latter assumption has never been tested, and is the central problem tackled in this study. The former assumption might be valid for bedrock channels with very low rates of sediment supply and negligible alluvial deposits (the "bedrock channels" as defined by Howard [1998]). However, the ubiquitous existence of alluvial deposits in bedrock channels, especially in mountain belts (where arguably understanding bedrock channel dynamics matters most), demonstrates that there is at least a range of discharge events for which $Q_{s} / Q_{t}>1$. As a consequence it cannot be assumed that $Q_{s} / Q_{t}$-dependent cover models can be safely upscaled to longer time scales using an effective discharge approach [Cowie et al., 2008; Crosby et al., 2007; Gasparini et al., 2006; Sklar and Dietrich, 2006; Turowski et al., 2007; Whipple and Tucker, 2002]. A proper upscaling should at least be tried once to verify this assumption and define the minimum time scales at which an effective model can be defined.

[7] In this study, I address the long-term resulting cover effect $\bar{C}_{v}$ of short-term stochastic supply of water and sediment to channels by using a new numerical model of bedrock channel width and profile evolution calculated at daily time scale (code SSTRIM, Stochastic Sediment Transport and River Incision Model). The modeling strategy that I followed is based on three elementary mechanisms that are likely fundamental for the long-term dynamics of bedrock channels: (1) combination of transport threshold and daily stochastic variations in water discharge and sediment supply, (2) free evolution of width and slope as a function of bed and bank incision rate and (3) explicit treatment of alluvial thickness evolution through time and its consequence on the bed incision reduction.

[8] I start by describing the numerical model and how the cover effect at daily time scale can be cast in terms of alluvial cover thickness. Then, I use this model to explore the steady state geometrical configuration of a model bedrock channel reach submitted to a uniform uplift rate, and its relationship to changes in $\bar{Q}_{s}$, changes in the variability of water discharge, and the degree of nonlinearity between sediment supply rate and water discharge. Model results are divided in two parts: first, I show how the long-term cover effect operates at short time scales, and the specific role of extreme events. Then, I focus on the resulting long-term cover effect law at steady state $\bar{C}_{v}=f\left(\bar{Q}_{s} / \bar{Q}_{t}\right)$ and how it compares with the linear and exponential decrease cover models. As these two models are deficient, I finally suggest improved modeling strategies to simulate bedrock channel dynamics over the long term.

[9] I have limited the scope of this study mainly to steady state channels, because it allows me to study the impact of boundary conditions and specific features of the model definition (static versus dynamic cover for instance) on cover response, in a simpler framework. Nevertheless, at the end of this study I discuss the applicability of the steady state derived cover effect law $\bar{C}_{v}=f\left(\bar{Q}_{s} / \bar{Q}_{t}\right)$ during transient channel adjustment.

\section{Description of the Numerical Model SSTRIM}

\subsection{Geometry and Mass Balance Equations}

[10] The model is inspired by the bedrock evolution model developed by Stark [2006], and the alluvial channel model by Cantelli et al. [2007]. It consists of a series of $n$ 


\section{A) Cross-section geometric variables}

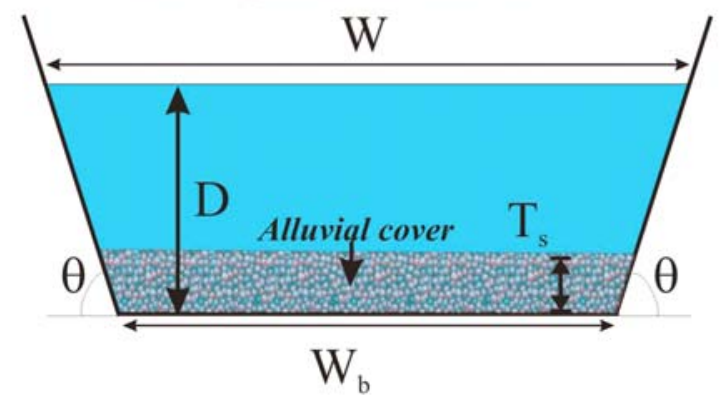

B) Alongstream organization of sections

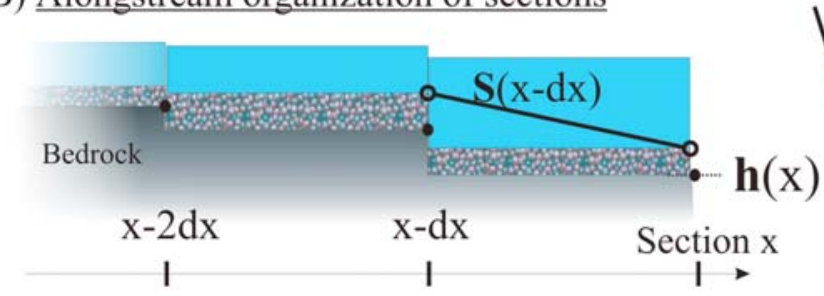

C) Controls on width variation

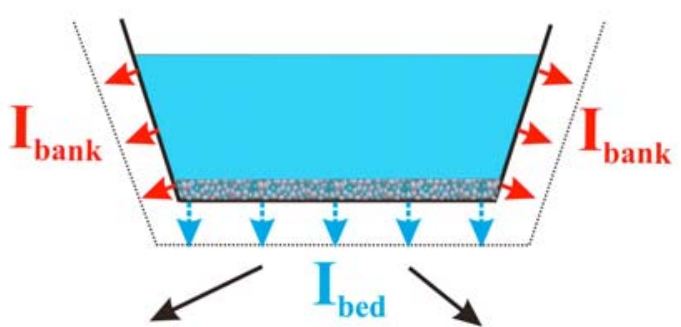

Narrowing $\mathrm{I}_{\text {bed }}>\mathrm{I}_{\text {bank }} / \cos (\theta)$

Widening $\mathrm{I}_{\mathrm{bed}}<\mathrm{I}_{\text {bank }} / \cos (\theta)$
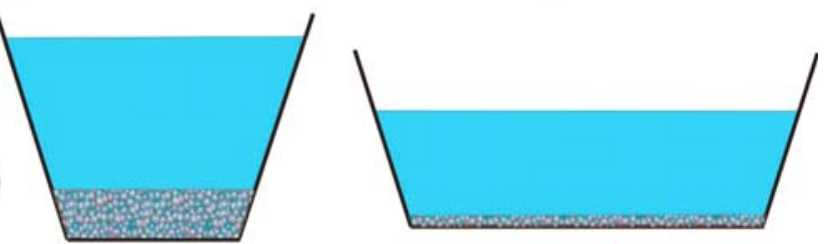

Figure 2. (a and b) SSTRIM numerical model geometry and variables and (c) width variations. Vertical dimensions are exaggerated. Bank angle is constant. Note that channel widening and narrowing affect water depth (for the same discharge) but also sediment thickness for the same volume per unit length of channel.

trapezoidal cross sections set apart by a distance $d x$ along the downstream direction $x$ (Figure 2). Each cross section is symmetrical and characterized by a constant bank angle $\theta$, a basal elevation $h(x)$, a basal width $W_{b}(x)$, a mean alluvial cover thickness $T_{s}(\mathrm{x})$, and a longitudinal slope $S(x)$ computed in the downstream direction between 2 sections (Figure 2). Following Stark [2006], the evolution of the bedrock cross section geometry at a distance $x$ is governed by two mass balance equations:

$$
\begin{gathered}
\frac{d h(x)}{d t}=U(x)-I_{b e d}(x), \\
\frac{d W_{b}(x)}{d t}=2\left(\frac{I_{\text {bank }}(x)}{\sin \theta}-\frac{I_{b e d}(x)}{\tan \theta}\right),
\end{gathered}
$$

where $U(x)$ is the vertical uplift rate and $I_{b e d}(x)\left(I_{\text {bank }}(x)\right)$ is the mean bed (bank, respectively) incision rate. An additional mass balance on the transported sediment controls the temporal evolution of the volume of sediment cover $\operatorname{Vol}(x)$ stored between two sections:

$$
\frac{d \operatorname{Vol}(x)}{d t}=Q_{s}(x-d x)+\beta q_{\text {lat }}(x) d x-Q_{s}(x),
$$

where $\beta$ is the bed load fraction of the sediment supply, $q_{\text {lat }}(x)$ is the lateral supply of sediment per unit length of channel between $x$ and $x-d x$, and $Q_{s}(x)$ is the total volumetric bed load flux at a distance $x$. The variation of $\operatorname{Vol}(x)$ is translated into a variation of mean sediment thickness $T_{s}(x, t)$ by assuming that the sediment is uniformly distributed over the section and along a distance $d x$ upstream of the section $x$, with a packing density of 0.7 . I assume that bed and bank erosion produces suspended sediment that does not enter into equation (5).

[11] Whatever the bank angle, a calculation of the equivalent at-a-station hydraulic geometry for a trapezoidal channel, using a Manning equation predicts that flow width $\mathrm{W}$ is barely dependent on discharge at low flows $\left(W \sim W_{b}\right)$, and tends asymptotically toward a power law scaling $Q^{0.35}$ for large discharges. This asymptotic behavior corresponds to the average hydraulic geometry of bedrock rivers in Taiwan (exponent is $0.34 \pm 0.1$ ) [Turowski et al., 2008a]. Hence the trapezoidal cross section appears to be a good approximation of bedrock channel geometry, at least in Taiwan.

[12] Contrary to Stark [2006], I do not consider the development of meandering, and the channel stays permanently straight. The model formulation also assumes that flow always occupies the entire bed width. As such the model deals with narrow valleys where the channel width is most of the time equal to valley width and where lateral migration of an inner channel is minor [Lancaster, 2008]. While this is a safe assumption for rapidly incising rivers such as the Liwu river, which generally lacks a well defined inner channel, the model predictions are likely biased with increasing width/depth ratio. In these regimes, low-flow incision or transport might be underestimated because flow depth is smaller than would have been predicted if flow was concentrated into a narrower channel. Hence, part of the channel bottom could actually be in transport or incision, while the model assumes no incision. I have no simple way to assess the error induced by this simplifying assumption, and I thus assume that for width/depth ratio larger than 100150 (calculated for the mean annual discharge), model predictions should not be used quantitatively. However, I present the data as it helps to understand the asymptotic 
behavior of the numerical model, and caution on its use where necessary in the text.

[13] Inherent to the cross section geometry is the assumption that an average bed incision, sediment transport rate or cover effect can be defined at the length scale of $W_{b}$. Field measurements of bed load impact rates on the bed exhibit a strong lateral gradient even with a relatively flat bed [Turowski and Rickenmann, 2008], likely commensurate with the horizontal gradient in fluid velocity and influenced by local bed roughness variations. Flume experiments also exhibit significant lateral variations in transport and incision [Chatanantavet and Parker, 2008; Finnegan et al., 2007; Johnson and Whipple, 2007].These lateral variations cannot be captured in this model, and I assume that their transversal spatial mean can be related to mean parameters of the flow. This is where the difference with a real 2-D cross section model computing the parameters of the flow locally is the most profound [Wobus et al., 2006].

[14] Equations (3) and (4) capture in a simple way the effect of bed and bank erosion in governing channel width dynamics: widening occurs if $I_{\text {bank }}>I_{\text {bed }} \cos \theta$, and narrowing if $I_{\text {bank }}<I_{\text {bed }} \cos \theta$ (Figure 2c). Three different steady state configurations can thus be defined: (1) a topographic steady state for which $U=I_{\text {bed }}$ (steady state profile), (2) a crosssectional steady state when $I_{\text {bank }}=I_{\text {bed }} \cos \theta$ (steady state width), and (3) a complete steady state of the channel when the mean long-term value of $\bar{I}_{b a n k}=U \cos \theta$ and $\bar{I}_{b e d}=U$ for each section.

[15] Equations (3) and (4) form a simple detachmentlimited mass balance for bedrock channel evolution [Howard and Kerby, 1983], and equation (5) is an Exner mass balance equation [Paola and Voller, 2005] for the alluvial cover evolution. Even though equation (5) resembles a transportlimited model, it only pertains to the alluvial cover. The notion of detachment-limited or transport-limited model refers in that case to the mass balance (i.e., the mass of sediment in active transport through the channel is limited by a lack of availability in the channel in the detachment-limited case, but by the transport capacity of the flow in the transportlimited case). But the same terminology has also been used to define the configuration of channels at steady state, and their sensitivity to sediment supply. In particular, there is a profound difference between a channel whose configuration is only governed by local flow variables (bed shear stress typically), and one in which it is a combination of local flow variables and upstream derived sediment supply rate. In this latter case, a particular configuration arises for steady state channel geometry that is set such that $\bar{Q}_{t}$ equals $\bar{Q}_{s}$. These have been referred to as "transport-limited bedrock channels" [Brocard and van der Beek, 2006; Johnson and Whipple, 2007; Whipple and Tucker, 2002], even though their mass balance is detachment limited. To avoid any confusion in the course of the paper, I call a steady state incising bedrock channel that strictly verifies $\bar{Q}_{t}=\bar{Q}_{s}$ a "transport capacitylimited channel." For $\bar{Q}_{s}<\bar{Q}_{t}$, I follow the classification suggested by Whipple and Tucker [2002] and use the term "detachment-limited channel" for channels whose steady state configuration is independent of $\bar{Q}_{s}$, and "hybrid channel" otherwise. I provide evidence in this study of the necessity to distinguish these three types of channel configuration. Note, that a subcategory of "hybrid channels" has been recently introduced [Johnson et al., 2009] to char- acterize incising bedrock channels in which $\bar{Q}_{s}$ is slightly less than $\bar{Q}_{t}$. These channels have been called "sediment load dominated channels."

\subsection{Constitutive Equations for Hydraulics}

[16] For a given discharge $Q(\mathrm{x})$, flow is supposed to be uniform and steady at the scale of $d x$. Flow depth $D(x)$ is calculated using a Manning friction law:

$$
V=\frac{1}{n} R^{2 / 3} S^{1 / 2}=\frac{Q}{A_{w}},
$$

where $V$ is mean flow velocity, $n$ is the Manning coefficient, $R$ is the hydraulic radius, $S$ is channel slope and $A_{w}$ is the wetted surface area. By using the hydraulic radius explicitly, friction on the banks is factored into the calculation of flow depth and matters when width/depth ratio becomes small (i.e., $W / D<20-30$ ). Equation (6) is solved iteratively to get $D(x)$ at a precision of $1 \mathrm{~cm}$. I simplify the problem by assuming that (1) the bed and bank roughnesses are equal and (2) that the Manning coefficient is independent of discharge or state of the bed cover (alluvial, bedrock, or partially covered), which allows to use a representative value of $n=0.05$ (typical of cobble-bed, step-pool rivers).

[17] Because of secondary currents developing at the wall/ bed intersection, the analytical prediction of mean bed and bank shear stress even in a simple trapezoidal cross section with uniform roughness remains difficult [Knight et al., 2007]. The change in the partitioning between mean bed shear stress $\tau_{\text {bed }}$ and mean bank shear stress $\tau_{\text {bank }}$ with width/ depth ratio has been documented in flume experiments [Flintham and Carling, 1988]. Rather than assuming a constant ratio of $\tau_{\text {bed }} / \tau_{\text {bank }}$ [Cantelli et al., 2007], I use an empirical model for trapezoidal channels [Flintham and Carling, 1988; Knight, 1981; Knight et al., 1984]:

$$
\begin{gathered}
\tau_{\text {bank }}=\rho g D S \frac{F_{w}}{2}\left(\frac{W}{D} \sin \theta-\cos \theta\right), \\
\tau_{\text {bed }}=\frac{\rho g}{2} D S\left(1-F_{w}\right)\left(1+\frac{W \tan \theta}{W \tan \theta-2 D}\right), \\
F_{w}=1.78\left(\frac{W}{D} \sin \theta-2 \cos \theta+1.5\right)^{-1.4},
\end{gathered}
$$

where $F_{w}$ is the proportion of shear force carried by the banks. Typically, when $W / D>10$, the bank shear stress represents $10 \%$ of the total shear stress and becomes rapidly negligible when $W / D>40$. As my interest is to reveal some of the nonlinearities arising from the coupling between dynamic channel width and discharge variability, the exact formulation of the partitioning is not critical to the study as long as the bank shear stress decreases with $W / D$ and bed shear stress converge toward $\rho g D S$ for very large $W / D$. Using an analytical approximation of mean bed and bank shear stresses allows running the model at a daily time step pertinent to the problem of discharge variability.

\subsection{Constitutive Equations for Bed and Bank Erosion}

[18] The definition of bedrock incision laws is an active topic of research, and no universal law has emerged from 
Table 1. Parameters Used in the Simulations ${ }^{\mathrm{a}}$

\begin{tabular}{|c|c|}
\hline Parameter & Value \\
\hline \multicolumn{2}{|l|}{ Constitutive } \\
\hline Bank angle, $\theta$ & $60^{\circ}$ \\
\hline Median grain size $(\mathrm{m}), D_{50}$ & 0.05 \\
\hline Manning coefficient, $n$ & 0.05 \\
\hline Sediment density $\left(\mathrm{kg} / \mathrm{m}^{3}\right), \rho_{s}$ & 2700 \\
\hline Sediment packing density & 0.7 \\
\hline Critical Shield's stress, $\tau_{\mathrm{c}}{ }^{*}$ & 0.03 \\
\hline Sediment transport coefficient, $\chi_{\text {sed }}$ & $10^{-6}$ \\
\hline Bank erosion efficiency, $\chi_{\text {bank }}$ & $5.10^{-12}$ \\
\hline Bed erosion efficiency, $\chi_{\text {bed }}$ & $10^{-11}$ \\
\hline Shear stress exponent, $a$ & $1(1.5)$ \\
\hline Static cover efficiency, $\xi$ & 2 \\
\hline \multicolumn{2}{|l|}{ Numerical solution } \\
\hline Time discretization, $d t$ & 1 day \\
\hline Spatial discretization, $d x$ & $100 \mathrm{~m}$ \\
\hline Number of cross sections & $5(31)$ \\
\hline Duration of simulations & $10^{5}$ years \\
\hline \multicolumn{2}{|l|}{ Boundary conditions } \\
\hline Uplift rate, $U(\mathrm{~mm} / \mathrm{yr})$ & $1(0.5,5)$ \\
\hline Mean runoff rate $(\mathrm{m} / \mathrm{yr}), \bar{r}$ & 2 \\
\hline Drainage Area $\left(\mathrm{m}^{2}\right), A$ & $10^{7}$ \\
\hline Discharge variability, $k$ & $1(0.5,2)$ \\
\hline Rating exponent, $m$ & $2(1,1.5,3)$ \\
\hline Mean sediment supply $\left(\mathrm{m}^{3} / \mathrm{s}\right)$ & $0-0.02$ \\
\hline
\end{tabular}

${ }^{\mathrm{a}}$ Values in brackets correspond to alternative parameter values tested.

the theoretical [Lamb et al., 2008; Sklar and Dietrich, 2004; Whipple et al., 2000], experimental [Finnegan et al., 2007; Johnson and Whipple, 2007; Lamb et al., 2008; Sklar and Dietrich, 2001], or field data analysis [Hartshorn et al., 2002; Johnson et al., 2009; Lavé and Avouac, 2001; Tomkin et al., 2003; van der Beek and Bishop, 2003]. Of the dominant factors likely to play a role in bedrock incision, sediment tools and cover effects [Sklar and Dietrich, 2001], shear stress [Howard and Kerby, 1983; Whipple et al., 2000] and a critical threshold for incision or transport are expected to be important [Lague et al., 2005; Snyder et al., 2003], especially when discharge variability is taken into account. The role of sediment as tools for abrasion or facilitating plucking is not factored in this set of simulations [Lamb et al., 2008; Sklar and Dietrich, 2004; Whipple et al., 2000]. This simplification allows me to break down the problem of bedrock channel dynamics into individual elementary problems for which the response to stochastic forcing can be understood. Adding too much complexity (arguably at the expense of realism) could obscure this response and limit our appreciation of the dynamics of this system to a superficial view.

[19] The bed and bank incision law are thus defined as a threshold shear stress incision law [Hancock and Anderson, 2002; Howard and Kerby, 1983; Lavé and Avouac, 2001]:

$$
\begin{gathered}
I_{b e d}=\chi_{\text {bed }} C_{v} C_{d}\left(\tau_{\text {bed }}-\tau_{c}\right)^{a}, \\
I_{\text {bank }}=\chi_{\text {bank }} \tau_{\text {bank }}^{a}, \text { if } \tau_{\text {bed }}>\tau_{c},
\end{gathered}
$$

where $\chi_{z}$ is the erosion coefficient of the bed and bank, respectively, $\tau_{c}$ is a critical shear stress for bedrock incision, $C_{v}$ is the incision reduction by static cover, $C_{d}$ is the potential reduction of incision by dynamic cover (see details below) [Turowski et al., 2007] and $a$ an exponent that I assume to be equal to 1 for all the simulations, except in one case where it is set to $3 / 2$. I assume for simplicity that the critical shear stress for bedrock incision is equal to the critical shear stress for sediment transport. Arguably, $\tau_{c}$ is expected to depend somehow on the bedrock properties, but there is no way to constrain this dependency at present. I also assume that bank incision cannot occur if sediment is not transported. For simplicity, a critical shear stress was not considered in equation (11). Although the steady state geometry would be modified by adding $\tau_{c}$ to equation (11), it does not change the alluvial cover dynamics or the resulting long-term cover effect. $\tau_{c}$ is evaluated using a Shields stress criterion taken to be $\tau_{c}{ }^{*}=0.03$ :

$$
\tau_{c}^{*}=\frac{\tau_{c}}{g\left(\rho_{s}-\rho_{w}\right) D_{50}},
$$

where $g$ is the acceleration of gravity, $\rho_{s}$ and $\rho_{w}$ are sediment and water density, respectively (taken to be equal to 2700 and $1000 \mathrm{~kg} / \mathrm{m}^{3}$ ), and $D_{50}$ is the median grain diameter on the bed. $D_{50}$ is a parameter that is fixed in the numerical model, but could vary along stream if necessary. In the following calculations, $D_{50}=5 \mathrm{~cm}$, which corresponds to $\tau_{c}=25 \mathrm{~Pa}$, except for one simulation in which $\tau_{c}=0$. Here $\chi_{b e d}$ and $\chi_{\text {bank }}$ have been chosen by trial and error in order to get meaningful results in terms of width, depth and slope of a prototype river like the Liwu river at Lushui station (Figure 1 and Tables 1 and 2). I stress that this is not a proper calibration to the Lushui site, but a simple approach to get an order of magnitude of the range of reasonable values given that sediment supply (which is not well constrained) is playing a role in the steady state incision geometry when cover effects are factored in. I found that to get a reasonable width/depth ratio and slope, $\chi_{\text {bank }}$ has to be twice or even an order of magnitude less than $\chi_{\text {bed }}$. The reason for this difference in incision efficiency is not clear. Presumably, this might reflect the simplified cross-sectional geometry or simplified shear stress calculation. Another possibility is that alluvial cover inhibits bank incision for large sediment thicknesses. This is not yet factored into the numerical model. Alternatively, this might indicate that tool effects are important in Liwu and increase the efficiency of bed incision (high concentration and high velocity of particles) compared to bank incision (lower concentration and velocity on average). If so, using differential incision efficiency for bed and bank captures this effect. Note that the simulations are run for a drainage area of $10 \mathrm{~km}^{2}$ and a smaller runoff rate than for Lushui simply because the response time of the channel is much shorter $(\sim 20,000$ 30,000 years) in that case, allowing me to test more model parameters. As a consequence, the slope and width values presented in the remaining part of this study should not be compared to the Liwu river at Lushui.

[20] The bed erosion coefficient $\chi_{\text {bed }}$ can be reduced by the presence of a static alluvial cover over part or all the bed. As the mean thickness of sediment $T_{s}$ stored in any part of the channel is tracked, one does not have to rely on a relationship between sediment flux and sediment transport capacity to compute the static cover effect. Partial static cover occurs statistically when $T_{s} / D_{50}<1$ and full spatial cover when $T_{s} / D_{50} \geq 1$. The average incision reduction (that I call the cover effect $C_{v}$ ) is expected to increase linearly with the extent of surface covered (i.e., $T_{S} / D_{50}$ ) in the partial 
Table 2. Lushui Discharge and Geometrical Parameters and Steady State Predictions of the Model

\begin{tabular}{|c|c|c|}
\hline Parameter & Value & Predicted \\
\hline \multicolumn{3}{|l|}{ Estimated boundary conditions } \\
\hline Uplift rate $^{\mathrm{a}}$ & $5 \pm 1 \mathrm{~mm} / \mathrm{yr}$ & - \\
\hline Discharge variability ${ }^{\mathrm{b}}, k$ & $0.85 \pm 0.12$ & - \\
\hline Drainage area & $435 \mathrm{~km}^{2}$ & - \\
\hline Mean runoff $\bar{r}$ & $2.4 \mathrm{~m} / \mathrm{yr}$ & - \\
\hline Basin wide denudation rate ${ }^{c}$ & $12 \mathrm{~mm} / \mathrm{yr}$ & - \\
\hline Rating exponent ${ }^{\mathrm{c}}, m$ & 2 & - \\
\hline Bed load fraction ${ }^{\mathrm{c}}$ & 0.3 & - \\
\hline \multicolumn{3}{|l|}{ Measured geometrical parameters } \\
\hline Slope $^{\mathrm{d}}$ & $0.02 \pm 0.002$ & 0.013 \\
\hline Basal width ${ }^{\mathrm{e}}, \mathrm{W}_{\mathrm{b}}$ & $30 \pm 3 \mathrm{~m}$ & $24.85 \mathrm{~m}$ \\
\hline Width depth ratio ${ }^{\mathrm{f}}$ at $60 \mathrm{~m}^{3} / \mathrm{s}$ & $37 \pm 11$ & $24 \pm 3.2$ \\
\hline \multicolumn{3}{|l|}{ Other model outputs } \\
\hline $\begin{array}{l}\text { Mean long-term alluvial thickness } \\
\bar{T}_{s}\end{array}$ & - & $1.3 \mathrm{~m} \pm 5.8 \mathrm{~m}$ \\
\hline Mean cover effect $\bar{C}_{v}$ & - & 0.48 \\
\hline
\end{tabular}

${ }^{\mathrm{a}}$ Derived from steady-state assumption and field measurements of incision rates averaged over 5 years [Hartshorn et al., 2002; Turowski et al., 2008b].

${ }^{\mathrm{b}}$ Lague et al. [2005].

${ }^{c}$ Derived from suspended load measurement over 30 years and comparison with reservoir accumulation [Dadson et al., 2003].

${ }^{\mathrm{d}}$ Measured over a $1 \mathrm{~km}$ length on a $30 \mathrm{~m}$ DEM [Hartshorn et al., 2002].

${ }^{\mathrm{e}} \mathrm{S}$ ee Turowski et al. [2008b] for a cross section of the reference site. Error corresponds to the uncertainty in defining the base width of the equivalent trapezoidal model.

${ }^{\mathrm{f}}$ Width estimated from photographs at the corresponding discharge, and corresponding depth inferred from the surveyed cross-channel section ( $30 \%$ conservative error in the estimation). Error in numerical model prediction corresponds to standard deviation of 200 data factoring cover variations

${ }^{\mathrm{g}}$ Variability corresponds to the standard deviation of 5000 daily measurements of alluvial cover spread over 50,000 years.

regime [Sklar and Dietrich, 2004], and completely suppress incision after a mean thickness of $\xi$ grains has developed. As the bed alluvial thickness is likely variable at the scale of a cross section, one expects that erosion could occur with a mean thickness of several grains as bedrock could still be locally exposed in patches (see Figure 1 for instance). This idea, put forward in the exponential cover model by Turowski et al. [2007] (although it is not strictly comparable because it is not expressed as a function of $Q_{s} / Q_{t}$ ), translates into an exponential model for the reduction of incision by mean cover thickness (Figure 3):

$$
C_{v}=\exp ^{-\frac{1}{\xi} \frac{T_{s}}{D_{50}}} .
$$

Equation (13) is similar to the alluvial cover reduction effect postulated by Howard [1998] (equation (23)), and used by Hancock and Anderson [2002]. This is to date the only cover effect expressed in terms of the alluvial thickness sitting on the bed. I have also tested the specific role of the static cover expression by using a simpler linear decrease of incision, with complete incision inhibition at a thickness of $\xi$ grains (Figure 3). This latter case would resemble the concept of linear cover model introduced by Sklar and Dietrich [2004], even though it is not expressed as a function of $Q_{s} /$ $Q_{t}$. In the following calculations, I use $\xi=2$. Note that $\xi$ must not be confused with the thickness of sediment that could be scoured during a large discharge event: $\xi$ corresponds to the actual mean thickness of grains resting on the bed during a transporting event.
[21] The impact of the additional dynamic cover effect proposed by Turowski et al. [2007] has also been tested for one set of simulations using equation (2), with $v=1$. While the qualitative effect of a static alluvial cover has been demonstrated in laboratory experiments [Finnegan et al., 2007; Johnson and Whipple, 2007; Sklar and Dietrich, 2001], and is certainly active in natural rivers, the dynamic cover effect still lacks an experimental testing.

\subsection{Constitutive Equations for Sediment Transport Capacity}

[22] The total bed load transport capacity of a cross section is estimated using

$$
Q_{c}=W_{b f} \chi_{\text {sed }}\left(\tau_{\text {bed }}-\tau_{c}\right)^{3 / 2},
$$

where $W_{b f}$ is the width at the water-bed interface, $\chi_{\text {sed }}$ is a coefficient of transport that can be estimated from various bed load transport capacity laws [Fernandez-Luque and Van Beek, 1976; Meyer-Peter and Müller, 1948], and would typically be of the order of $10^{-6}$ to $10^{-5}$.

\subsection{Discharge and Sediment Supply}

[23] Daily variations in runoff are imposed in the model, which control the amount of water and sediment delivered in any location of the channel. The daily discharge $Q(x, t)$ is calculated according to the following equation:

$$
Q(x, t)=\bar{r} \cdot Q^{*}(t) \cdot A(x),
$$

where $\bar{r}$ is the mean annual runoff rate, $Q^{*}(t)$ is the daily discharge normalized by the mean annual discharge, and $A$ $(x)$ the drainage area that can be set arbitrarily, but was kept constant at $10 \mathrm{~km}^{2}$ in the series of simulations presented here. In all simulations but one, $Q^{*}(t)$ varies stochastically according to a frequency-magnitude distribution. To assess the effect of discharge variability, I also ran a series of experiment with constant discharge $\left(Q^{*}(t)=1\right)$. I used the two-parameter frequency-magnitude distribution of daily discharge events of the landscape evolution model Eros

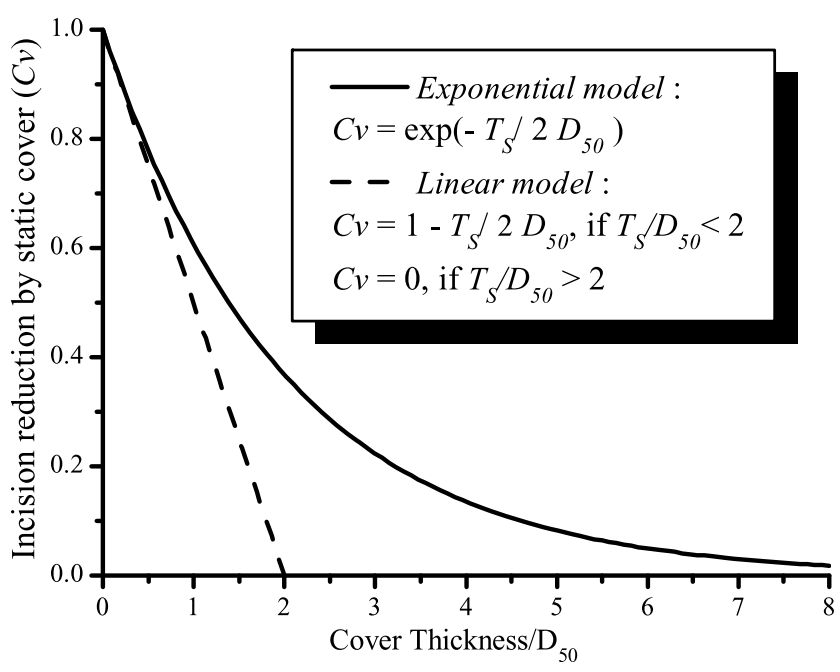

Figure 3. Laws of bed incision reduction by static alluvial cover used in the numerical model. 
[Davy and Crave, 2000; Lague et al., 2005]. It has been found to fit correctly the complete range of discharges in many locations, including mountain rivers [Lague et al., 2005] and the predicted power law tail of the distribution has been observed in many frequency-magnitude distributions of flood events in the United States [Molnar et al., 2006]. The probability density function (pdf) of daily normalized discharge $Q^{*}(x)$ is given by [Lague et al., 2005, equation (3)]

$$
p d f_{\bar{Q}, k}\left(Q^{*}\right)=\frac{k^{k+1}}{\Gamma(k+1)} \exp \left(-\frac{k}{Q^{*}}\right) Q^{*-(2+k)} d Q^{*},
$$

where $k$ is a parameter setting the discharge variability (note that the variability is greatest for small values of $k$ ). $\Gamma(k+1)$ is the gamma function and equals $k$ ! when $k$ is an integer. In nature, $k$ has been found to vary between 0.1 and 4 [Lague et al., 2005; Molnar et al., 2006]. Smaller values correspond to dry climates or monsoon dominated regimes, and larger values are more typical of humid temperate climate. In the simulations, $k$ is spatially uniform. The overall discharge distribution is thus controlled by 2 parameters: the mean annual runoff $\bar{r}$ and the discharge variability parameter $k$.

[24] At the beginning of each simulation, the cumulative distribution function of equation (16) is calculated and discretized on a logarithmic basis using $10^{5}$ intervals from $10^{-2}$ to $10^{4}$. Each time a normalized discharge has to be picked, a random number in the interval $[0 ; 1]$ is chosen, and the closest normalized discharge for which the CDF is equal to the random number is sought. Keeping in line with the simplest approach possible, temporal correlations between discharge events are neglected. The potential consequences of this simplification are discussed later in the paper.

[25] Sediment can be supplied to the model channel either from upstream in the uppermost section and/or laterally at any cross section. In this study I only consider supply from the uppermost section. The variability of sediment supply to the channel and the frequency of occurrence of extreme sediment deposits by large landslides are obviously important for the study of cover dynamics. Typically, in any location of a mountain river, the flux of sediment will depend on many parameters including hillslope sediment supply (locally and in the upstream catchment), storage and release in the upstream part of the channel, transport capacity of the section, bed armoring and roughness, among other parameters. Some elements of this complexity are built into the model such as the limitation of bed load flux by transport capacity, and the upstream (or local) storage of sediment via the tracking of the sediment volume stored upstream. However, the remaining complexity cannot readily be captured by a simple model of sediment supply to the channel. Hence, I suppose that bed load sediment supply $Q_{s}(t)$ to the uppermost section obeys a general power law relationship with discharge:

$$
Q_{\mathrm{s}}(t)=k_{\mathrm{sup}} Q^{*}(t)^{m},
$$

where $k_{\text {sup }}$ is a constant scaling factor, and $m$ may be viewed as a rating exponent. This supply of sediment is rapidly modulated by the storage and release of sediment (depending on the along-stream variations of transport capacity) of the first sections of the channel as it would be in nature. For instance, because equation (17) does not have a critical discharge, the very low discharge events are always net depositing in the uppermost cross section, but for the immediate downstream sections, sediment supply will be modulated by sediment transport capacity: no sediment will be supplied to the downstream section if $\tau<\tau_{c}$, and the supply cannot exceed the transport capacity of the upstream section. This storage and release of sediment also induces a temporal decorrelation between the flux of sediment at the central cross section (the one I study) and water discharge such that equation (17) does not strictly apply at this section. Model results illustrate this aspect in section 3 .

[26] As will be shown in this paper, the choice of $m$ is important for the long-term dynamics of the channel, but I am not aware of published values that could be used to define a range of realistic values. While I use equation (17) as a simple way to understand the controls of the nonlinearity of sediment supply on cover dynamics, it actually bears a close relevance to two different aspects of sediment production and transport that can be used to estimate the likely range of $m$ in nature: the frequency-magnitude distribution of landslide volumes, and the measurements of bed load flux in rivers (rating curves). The former comparison is possible because the combination of equations (16) and (17) lead to a pdf of sediment supply to the channel that obeys asymptotically a power law distribution for large events:

$$
p d f\left(Q_{s}\right) \propto Q_{s}^{-\frac{k+1}{m}-1} .
$$

On a constant time basis, equation (18) can be compared to the pdf of sediment volume mobilized from large landslides. It also obeys a power law $p(V o l) \sim V o l^{\beta-1}$ [e.g., Malamud et al., 2004], where $\beta$ is an exponent that can be inferred from the pdf of landslide area and a simple scaling law between length and thickness of landslides [e.g., Hovius et al., 1997]. Field data suggests that $\beta$ could vary between 0.75 and 1 , with a typical value of 0.9 [e.g., Malamud et al., 2004; Stark and Hovius, 2001; Stark and Guzzetti, 2009]. This is confirmed by a recent model of landslide rupture and propagation [Stark and Guzzetti, 2009]. Note that in doing this comparison I do not assume that the physics behind the pdf of water discharge and landslide volume are identical. It is just to demonstrate that a given combination of $k$ and $m$ can produce a pdf of sediment supply to the channel that is typical of a natural reach whose bed load supply is dominated by local landsliding. Hence, if we consider a discharge variability parameter $k=0.85$ typical of the Liwu river [Lague et al., 2005] and $\beta=0.9, m$ should be close to 2. For lower discharge variability $(k>1), m$ could be larger than 3 . To get a realistic value of $\beta$ for the lowest discharge variability conditions ever measured $(k=0.1)$, it is extremely unlikely that $m$ could be smaller than 1.1.

[27] Other constraints on $m$ come from the measurements of equation (17) in rivers. Even if $m$ is not a rating curve exponent per se, it bears some relevance to the measured relationship between sediment flux and water discharge in supply limited rivers. Rating curves generally deal with suspended load, not total load, and in situ data on the relationship between bed load fluxes and discharge covering a large range of discharges are scarce. In Taiwan, suspended load measurements over 29 major watersheds exhibit a range of rating exponent between 1 and 2 (with a case at 3 ) 
[Dadson, 2004]. Seventeen years of bed load transport rate measurements in a small catchment of the Alps [Lenzi et al., 2004] suggest a value of $m \sim 3$. Bed load measurements in 24 rivers in Idaho gives values of $m$ varying between 1.5 and 3.9, with half of the data between 2 and 3 [Barry et al., 2004]. These results and the previous comparison with the frequency magnitude of landslide volumes, suggest that the natural range of $m$ should be between 1 and 3, with a higher probability for $m \geq 1.5$. I thus explored a range of $m$ between 1 and 3, with most of the simulation using $m=2$. I only consider bed load in the mass balance, as suspended load is assumed to be evacuated without significantly interacting with the alluvial cover.

[28] Using equation (17) imposes a complete correlation between sediment supply and discharge which is potentially an important oversimplification. For instance, seismic activity in mountain belts is going to affect this correlation. In extreme cases, earthquakes can increase the sediment concentration in rivers by a factor of four for several years [Dadson et al., 2004], compared to background levels. To test the importance of the correlation degree, I ran a series of simulations in which the supply of sediment is randomly drawn from the pdf resulting from the combination of equations (17) and (16). In that case, the long-term sediment supply and its pdf are identical to the purely correlated case, but because $Q_{s}$ is independent of $Q_{w}$ the concentration in sediment can be extremely variable. This configuration is clearly unrealistic, but allows testing how dependent model predictions are on the correlation degree between discharge and sediment supply at the uppermost section.

[29] In equation (17), if $m<k+1$, the mean long-term sediment supply $\bar{Q}_{s}(x)$ is given by [Lague et al., 2005, equation (18)]

$$
\bar{Q}_{s}(x)=\frac{\Gamma(k+1-m) k^{m}}{\Gamma(k+1)} k_{\text {sup }} .
$$

Equation (19) allows me to factor in the impact of discharge variability on $\bar{Q}_{s}(x)$ in order to compare simulations with identical long-term boundary conditions. If $m \geq k+1, \bar{Q}_{s}(x)$ becomes strongly dependent on the largest discharge occurring during the simulation (see discussion by Lague et al. [2005, equation (21)]). However, as a maximum discharge is imposed in the model, a correction factor can be calculated from a long-term simulation, and then factored into equation (17) to run simulations that have a specified longterm sediment supply.

\subsection{Numerical Solution, Boundary Conditions, and Parameters}

[30] The SSTRIM code is solved using a finite difference approximation and an explicit calculation scheme. At each time step, calculation starts by randomly picking a value for $Q^{*}(t)$ and computing the daily discharge using equation (15). The calculation progresses downstream. At any cross section, local channel slope is computed to calculate flow depth and the resulting bed and bank shear stresses (Figure $2 b$ ). Then, the mass balance of sediment is computed according to the difference in the sediment supplied from upstream (and locally stored in the static alluvial cover) and exported downstream (equation (5)). The downstream export is limited by the cross section transport capacity (equation (14)).
Alluvial cover thickness $T_{s}(x, t)$ is calculated from the volume of sediment not exported and used to compute the static cover effect according to equation (13). The exported volume of sediment $Q_{s}(x)$ is used to compute the dynamic cover effect from equation (2) (if this effect is operative). Then bed and bank incision are calculated and the channel elevation and width are updated according to equations (3) and (4).

[31] The boundary conditions are such that sediment is supplied only at the upstream section. The lowest cross section is set at a constant elevation and is always free of sediment (i.e., infinite transport capacity). This configuration is necessary to drive sediment transport and subsequent bedrock incision over the long term. All sections but the outlet are submitted to a uniform uplift rate U. I used a spatial discretization of $100 \mathrm{~m}$, a temporal discretization of 1 day and 5 cross sections. I present the geometric evolution of the central section. Unless otherwise specified, the data presented correspond either to a 50 year average of daily values, or to one daily value picked every 50 years. Initial conditions correspond to a constant width, slope and no cover for all sections. The choice of these values has no effect on the steady state configuration attained by the channel. The reference parameters and boundary conditions used in the simulation are given in Table 1.

\section{Predicted Regimes of Cover Dynamics at Steady State}

[32] I first present two simulations in detail to illustrate the transient dynamics of the model, and most importantly demonstrate that the model exhibits two different steady state cover dynamics: one in which the long-term cover effect is dominantly set by a permanent partial cover of the system ("permanent partial cover" regime), and one in which the long-term effect is dominated by an alternation of fully covered and fully exposed bedrock conditions ("intermittent cover" regime). I point out the origin of the difference and discuss the impact of various model parameters (rating curve exponent, correlation between sediment supply and discharge, long-term sediment supply, discharge variability, uplift rate) on the tendency for rivers to be dominated by the permanent or intermittent cover regime.

[33] To simplify the interpretation of the results, I define a convenient nondimensional number, the supply uplift ratio:

$$
\varphi=\frac{\bar{Q}_{s}}{U \cdot A},
$$

in which $A$ is the contributing upstream drainage area. By comparison to a steady state watershed eroding at uniform uplift rate $U, \varphi$ corresponds to the bed load fraction of sediment. In that case, $\varphi$ could thus possibly vary from 0 to 0.6 [Dadson et al., 2003]. As I vary $\bar{Q}_{s}$ independently of the local uplift rate $U, \varphi$ can be larger than 1 .

\subsection{Regimes of Steady State Alluvial Cover Dynamics}

[34] Figure 4 presents the temporal evolution of bed and bank incision rates and geometrical parameters for a linear rating curve $(m=1)$ and quadratic rating curve $(m=2)$. Each point represents a 50 years average of daily values. Uplift rate is $1 \mathrm{~mm} / \mathrm{yr}$, and $\varphi=0.5$ for both cases (i.e., $\bar{Q}_{s}$ is identical for the two simulations). The bed and bank incision rates reach an 

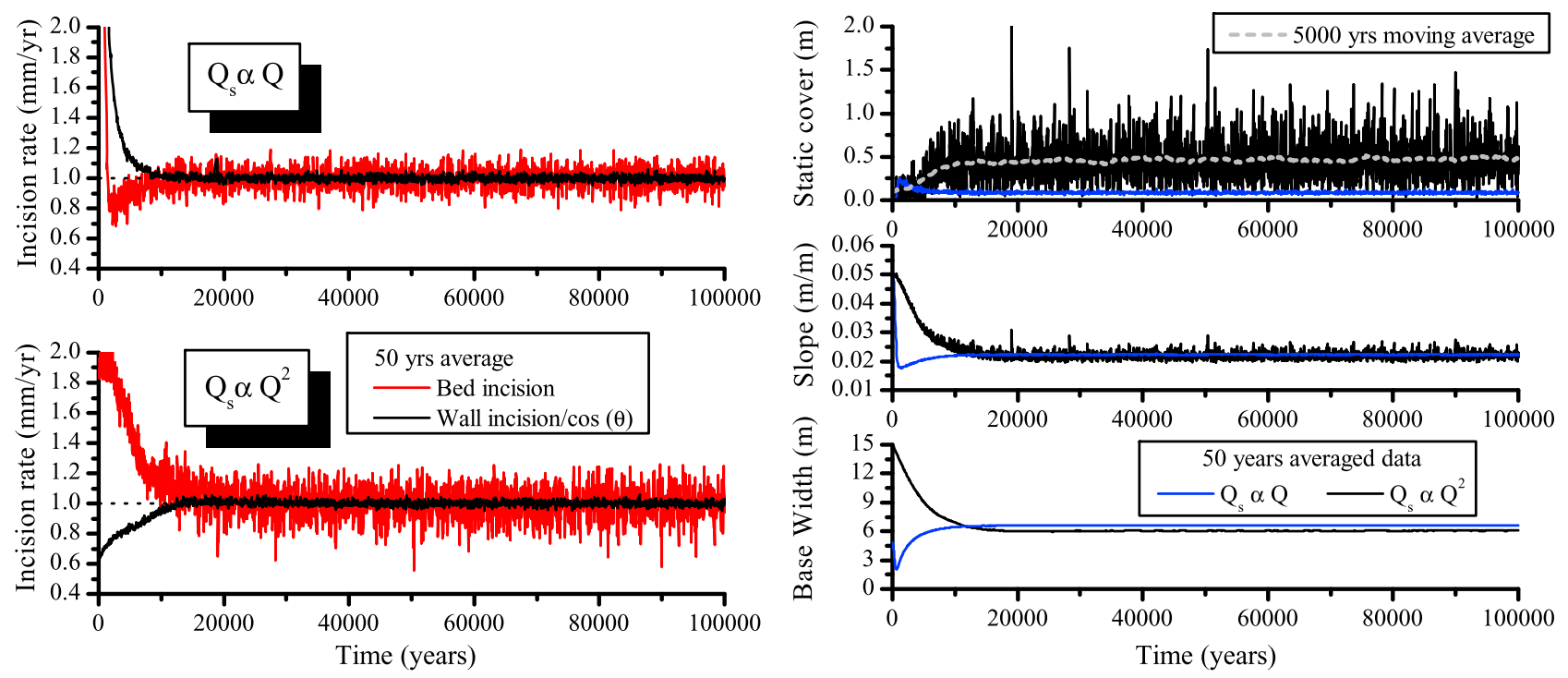

Figure 4. Evolution of geometric parameters and daily incision rates for different rating curve exponent $m$ but otherwise identical long-term boundary conditions. Data points represent 50 year averages of daily data. The degree of nonlinearity of sediment supply has a relatively small impact on channel geometry and response time but a strong impact on the short-term variability of sediment thickness (and thus slope, which factors in alluvial thickness longitudinal variation) and bed incision rate.

approximate steady state configuration around 18,000 years in both cases. Despite fluctuations of the bed incision rate ( $\sim 20 \%$ for $m=2$, and $\sim 10 \%$ for $m=1$ ), the mean long-term incision rates are set such that $I_{b e d}=\mathrm{U}$ and $I_{\text {bank }} / \cos (\theta)=\mathrm{U}$. In both cases, bank incision rates are less variable than bed incision, illustrating the effect of temporal shielding of the bed by sediment. The steady state slope and width are not significantly different ( $S$ is $2 \%$ larger and $W_{b} 10 \%$ larger for $m=1)$. However, the mean thickness of alluvial cover and its variability are very different. For $m=1, \bar{T}_{s}=0.085 \pm$ $0.009 \mathrm{~m}$, where thickness variability corresponds to the standard deviation of 5000 measurements taken on one day every year. For $m=2, \bar{T}_{s}=0.44 \pm 1.14 \mathrm{~m}$. By doubling the nonlinearity of the rating curve, the average cover thickness increases from roughly 1.7 grain diameters to almost 10 grains. Note that the fluctuations of channel slope are related to the variation of alluvial thickness. For this reason, channel slope is more variable at steady state for $m=2$ than for $m=1$.

[35] In terms of resulting long-term cover effect, $\bar{C}_{v}=$ 0.57 for $m=1$, and 0.71 for $m=2$, with a corresponding $\bar{Q}_{s} /$ $\bar{Q}_{t} \sim 0.8$ in both cases. Using previously proposed models (equations (1) and (2)) gives $\bar{C}_{v}=0.20$ for the linear decline model and $\bar{C}_{v}=0.45$ for the exponential decline model. Hence, the increased nonlinearity of the sediment supply/ discharge relationship reduces the long-term inhibiting effect of sediment transport. Critical to this study is the comparison between the model predictions resulting from daily dynamics and an equivalent average model. The long-term cover effect calculated with the mean thickness and equation (13), would correspond to $\bar{C}_{v}=0.43$ for $m=1$, and $\bar{C}_{v}=0.01$ for $m=2$. In this latter case, the corresponding mean cover effect would predict almost no incision at all. The cause of this difference is clearly illustrated by the temporal evolution of the daily cover effect (Figure 5): for $m=1$ a wide range of possible partial cover conditions occurs, while for $m=2$, the bed is either fully covered or completely bare. Figure 5 shows the frequency- magnitude distribution of the cover effect at steady state. For $m=2$, the long-term cover effect results from $64 \%$ of time during which the bed is completely or almost free of cover $\left(C_{v}>0.95\right)$, and $23 \%$ of time when bed incision is largely inhibited $\left(C_{v}<0.05\right)$. For $m=1$, the opposite happens: the bed is never fully covered, and it is cover free only $15 \%$ of the time (i.e., $C_{v}>0.95$ ). These results illustrate two different cover dynamics: (1) one in which the daily cover effect slightly fluctuates around its mean long-term value (permanent partial cover regime) and (2) a second in which the daily cover effect alternates between complete or null conditions, and in which the long-term value is set by the fraction of time when the bed is fully covered (intermittent cover regime).

\subsection{Origin of the Two Cover Dynamics Regime}

[36] The only parameter changed in the simulation discussed previously was the nonlinearity of sediment supply with discharge. The explanation of the two different regimes lies in a detailed analysis of the relationship between sediment supply and transport capacity, since the dynamics of the thickness of the alluvium depends on the ratio of these two parameters. Figure 6 shows the relationship between $Q_{t}$ and $Q^{*}$ that is an outcome of the model (and depends on the steady state channel configuration) and the imposed relationship between the sediment supply rate $Q_{s}$ and $Q^{*}$ (equation (17)). Note that the sediment supplied to the studied reach does not exactly correspond to equation (17) as it is already filtered by the two upstream cross sections. However, it is extremely close, and I use the imposed relationship as it is easier to understand. Because of the transport threshold, in low discharge events supply always exceeds transport capacity and sediment will tend to accumulate. However, for the quadratic rating curve, the contribution of low discharges to the long-term sediment supply is negligible compared to a linear rating curve. Thus, for the 

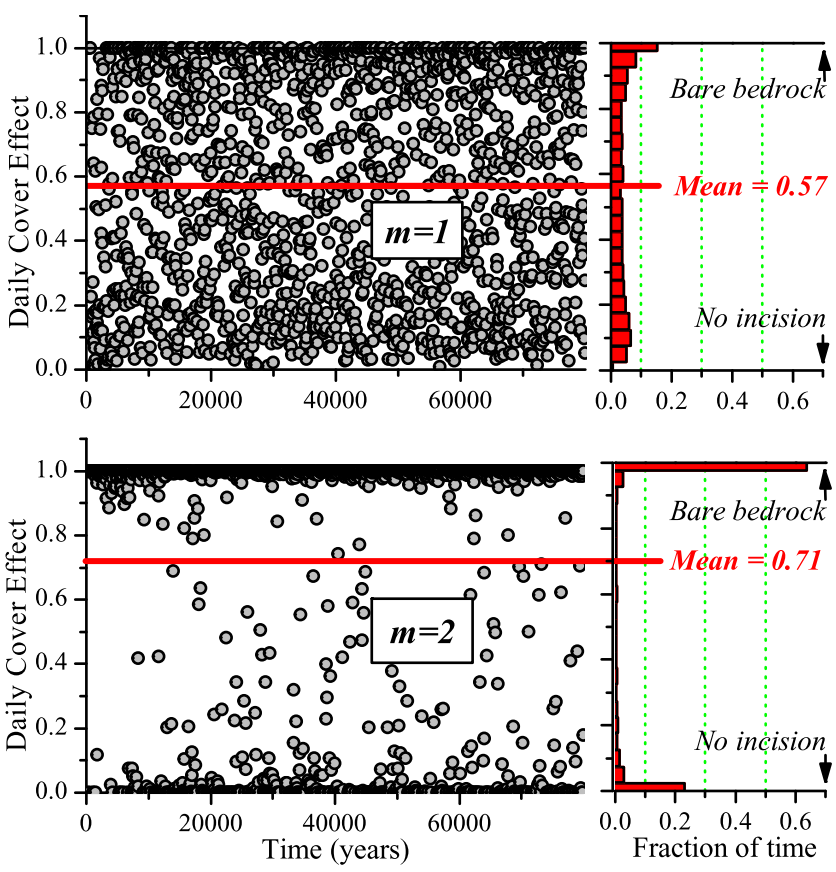

Figure 5. Variations of the daily cover effect at steady state illustrating the two end-member regime of short-term cover dynamics: (top) permanent partial cover $\left(m=1\right.$, i.e., $\left.Q_{\text {sup }} \alpha Q\right)$ and (bottom) intermittent cover $\left(m=2\right.$, i.e., $\left.Q_{\text {sup }} \alpha Q^{2}\right)$. Data points correspond to 1 daily value every 50 years. The right sides correspond to the frequency-magnitude distribution of daily cover effect at steady state.

same $\bar{Q}_{s}$, low discharge events below the critical discharge of entrainment bring about 10 times less sediment for $m=2$ than for $m=1$ (Figure 6). This tends to favor the maintenance of a cover free bedrock channel as sediment supply rate nonlinearity increases. The opposite happens for large discharges: in both cases, transport capacity increases approximately linearly. Hence, for $m=1, Q_{s} / Q_{t}$ is nearly constant with increasing discharge, smaller than one, and cover dynamics is mainly controlled by the variation of sediment supply at discharges around the critical discharge for transport. For $m=2, Q_{s} / Q_{t}$ decreases roughly as $1 / Q^{*}$, and large flood events are most of the time over capacity, while intermediate events are always under capacity.

[37] The resulting short-term dynamics for $m=2$ is shown in Figure 7. Flood events larger than the capacity discharge tend to deposit sediment, triggering the onset of a period of complete bed incision inhibition. Meanwhile smaller discharge events progressively remove the sediment cover and drive lateral erosion. When the cover has been depleted, a cover free bedrock surface tends to be preserved by the negligible deposits at low discharges until another large event brings in sediment. Note that net-eroding events tend to occur more often as channel bed slope increases because the critical discharge at which $\tau_{\text {bed }}>\tau_{c}$ is lower. This slope effect also helps to evacuate sediment in frequent intermediate discharges that are below capacity (Figure 6). The predictions illustrate the effect of history on incision inhibition by a static alluvial cover: it seems unlikely that the daily ratio $Q_{s} / Q_{t}$ can be used to predict the inhibiting effect of sediment transport. It requires the actual tracking of the state of the bed cover.

\subsection{Controls on the Dominance of the Permanent Versus Intermittent Cover Regime}

[38] I now study more systematically the various factors likely to influence the main regime cover dynamics. The results discussed above indicate that the intermittent cover regime will be favored by the nonlinearity between sediment supply and discharge, and the frequency of extreme discharges. Therefore, I study the impact of mean long-term sediment supply $\bar{Q}_{s}$, rating curve exponent $m$, discharge variability $k$ and the threshold shear stress of bed load transport $\tau_{\mathrm{c}}$. I also tested the impact of the modeled channel length and the correlation strength between supply of sediment and water discharge at the upstream entrance of the model domain. To quantify the relative importance of permanent partial versus intermittent cover, I define the parameter $\psi$ as the fraction of time for which $0.05<C_{v}<$ 0.95 at steady state, computed from 5000 daily measurements of $C_{v}$ spanning 100000 years. If $\psi>0.5$, the dominant mode is permanent partial cover, and vice versa.

[39] Figure 8 shows the variation of cover regime with $m$ and the degree of correlation ( 1 or 0 ) between $Q_{s}$ and $Q_{w}$ at the upstream entrance of the model domain. For the correlated case, a rapid transition occurs around $m=1.5-1.6$ between the permanent and intermittent cover regimes. It likely corresponds to the nonlinearity of the sediment supply law for which the frequency of intermediate events that are net eroding starts to be frequent enough to trigger the onset of the intermittent cover regime. These results are marginally affected by the length of the modeled channel. Using exactly the same pdf of sediment supply but completely uncorrelated to discharge, the previous relationship is smeared out (Figure 8), but not altered to the point that the permanent partial cover regime dominates. This underlines the fundamental role of the pdf of sediment supply to the river, and shows that the assumption of discharge-dependent sediment supply (equation (17)) is not the origin of the intermittent cover regime.

[40] The transition between permanent partial cover and intermittent cover will occur for lower values of $m$ at higher discharge variability (lower value of $k$ ). This effect is documented in Figure 9 which shows the variation of $\psi$ as a function of the supply uplift ratio $\varphi$ (equation (20)) for different combination of $m$, discharge variability $k$ and the threshold shear stress $\tau_{c}$. The data were generated by increasing $\bar{Q}_{s}$ for otherwise identical boundary conditions. Whatever the combination of parameters, the pattern of variation of $\psi$ with increasing sediment supply is identical: for almost negligible supply, $\psi$ is close to 0 , then it increases and peaks for values of $\varphi$ ranging from 0.7 to $2\left(\sim 0.1\right.$ for $\left.\tau_{c}=0\right)$ and tends toward 0 for large $\varphi$. The behavior at low values of $\varphi$ is simply related to the very low value of the mean cover effect, and the channel is always very close to a cover free configuration $\left(C_{v}>0.95\right)$. The opposite occurs for large $\varphi$ : the mean cover effect is very pronounced and the channel is frequently completely covered. In these two extremes whether the channel is in a permanent or intermittent cover regime is not relevant. The important domain is thus around the peak of $\psi$. Note that for $\varphi$ approximately larger than 3 , the 


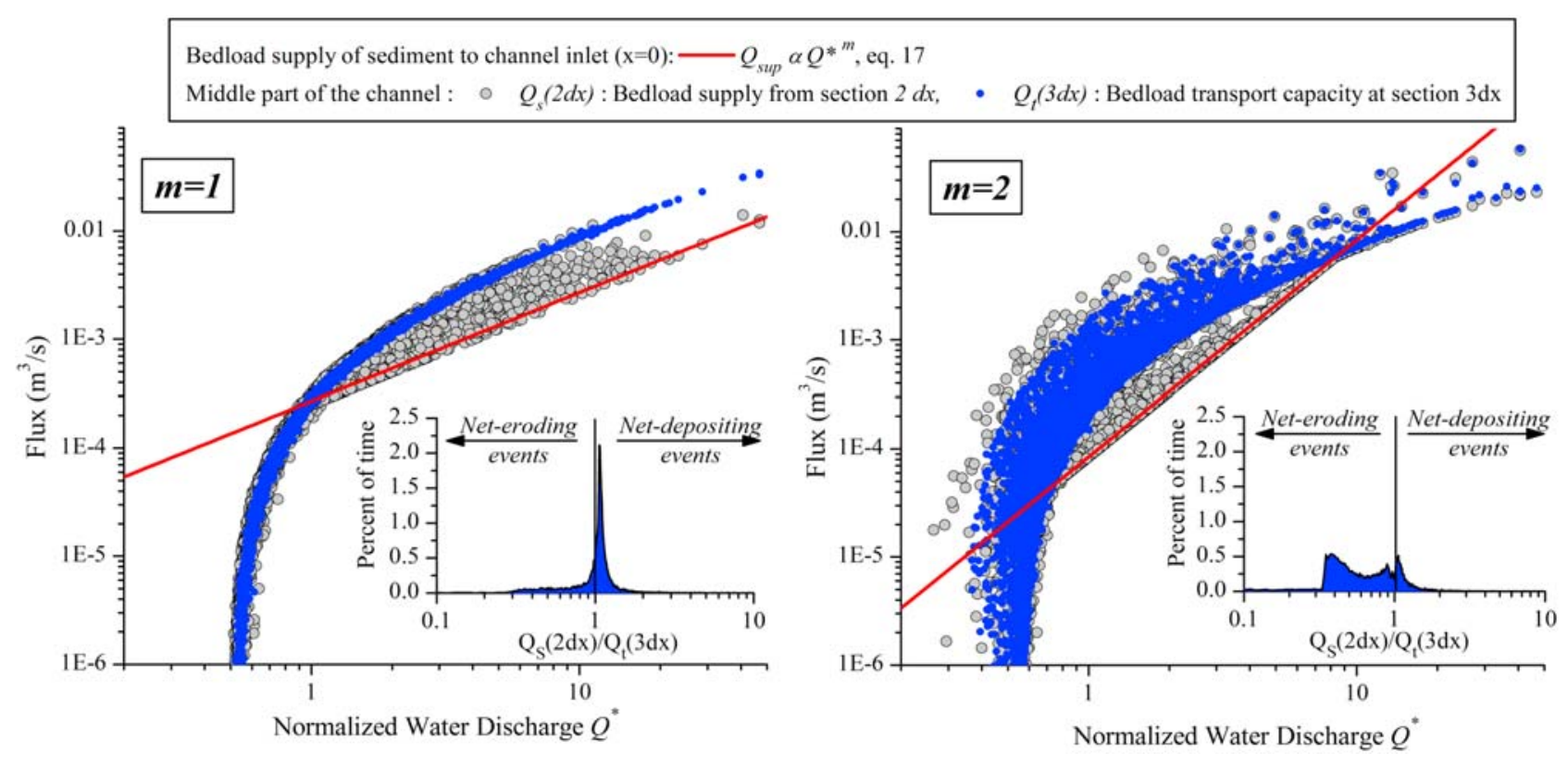

Figure 6. Daily supply of bed load flux and transport capacity variations with normalized water discharge in steady state configuration. Data corresponds to 30,000 daily values taken at 6 month intervals at the central section of the computational domain. For each simulation, the sediment supply rating curve (equation (17)) at the uppermost section $(\mathrm{x}=0)$ is also indicated. The bed load flux is a combination of this supply rating curve modulated by the upstream sediment storage and transport capacity. The variability in transport capacity for $m=2$ is related to alluvial thickness variation changing the channel slope at short time scale (see the slope variations in Figure 4).

width/depth ratio of the channel is often larger than 100 , and the assumption of equivalent channel and valley width is likely not true. Thus, although qualitatively expected, the predicted decrease of $\psi$ with large $\varphi$ may not be quantitatively correct.

[41] For $m=2$, the variability of discharge has a profound impact on the tendency to be in the intermittent cover regime. As discharge variability decreases $(k=2)$, extreme events leading to major phases of alluviation are rare, and the fraction of time where the channel is fully covered decreases compared to $k=1$. The opposite happens for larger variability $(k=0.5)$. Hence for $\varphi=0.4$ and $m=2$, while the channel is either fully covered or bare for about $95 \%$ of time in very variable climate $(k=0.5$, typical of monsoon regimes like in Taiwan), it is in either of these two configurations for only $60 \%$ of the time for $k=2$ (typical of temperate climate such as French Brittany or Great Britain).

[42] The critical shear stress of incipient transport has also a strong impact on the degree of intermittency of the alluvial cover. As expected from Figure 6, the larger is the threshold the greater will be the period when sediment will be deposited without being transported. This tends to favor an intermittent regime. Hence, even with very variable discharge $(k=1)$ and quadratic rating curve $(m=2)$, the cover dynamics can be at $50 \%$ in the partial cover regime when the threshold of transport is null. Note that the choice of the critical Shields stress of 0.03 and relatively small grain size $(5 \mathrm{~cm})$ is very conservative, and leads to a relatively low value of $\tau_{c}=25 \mathrm{~Pa}$. Hence, the threshold does not need to be high to shift the channel toward an almost complete intermittent cover dominated regime.
[43] Changing the steady state uplift rate does not have a major impact on the tendency to be in the intermittent cover regime. It means that even though channel geometry is varying with uplift rate, the change in width and slope does not fundamentally alter the cover dynamics mainly imposed by the variability of discharge, sediment supply and the threshold of transport. I discuss later in the paper the likely dominant regime of cover dynamics in natural bedrock channels by evaluating the limits of the modeling approach and the range of critical parameters in nature.

\section{Resulting Long-Term Cover Effect Law}

[44] Having studied the various modes of cover dynamics and their controls, I now turn toward the corresponding quantitative effect on incision efficiency, i.e., long-term cover. I will cast the results in terms of the under capacity degree $\bar{Q}_{s} / \bar{Q}_{t}$, as is usually the case [Gasparini et al., 2006; Sklar and Dietrich, 2004; Turowski et al., 2007; Whipple and Tucker, 2002]. However, contrary to the short-term relationship between the cover effect and the under capacity degree $Q_{s} / Q_{t}$ (such as the exponential decline model, equation (2)), where $Q_{s}$ and $Q_{t}$ are supposed independent, there are potential feedbacks between $\bar{Q}_{t}$ and $\bar{Q}_{s}$ at longer time scales. Consider for instance, a steady state channel incising at a rate $I$ and for which no sediment is supplied at the uppermost section $\left(\bar{Q}_{s}=0\right)$. This channel has a mean long-term transport capacity (that I term the reference transport capacity $\bar{Q}_{t}^{*}$ ) resulting from the combination of steady state channel geometry (width and slope), discharge parameters (mean and variability) and channel roughness. If 

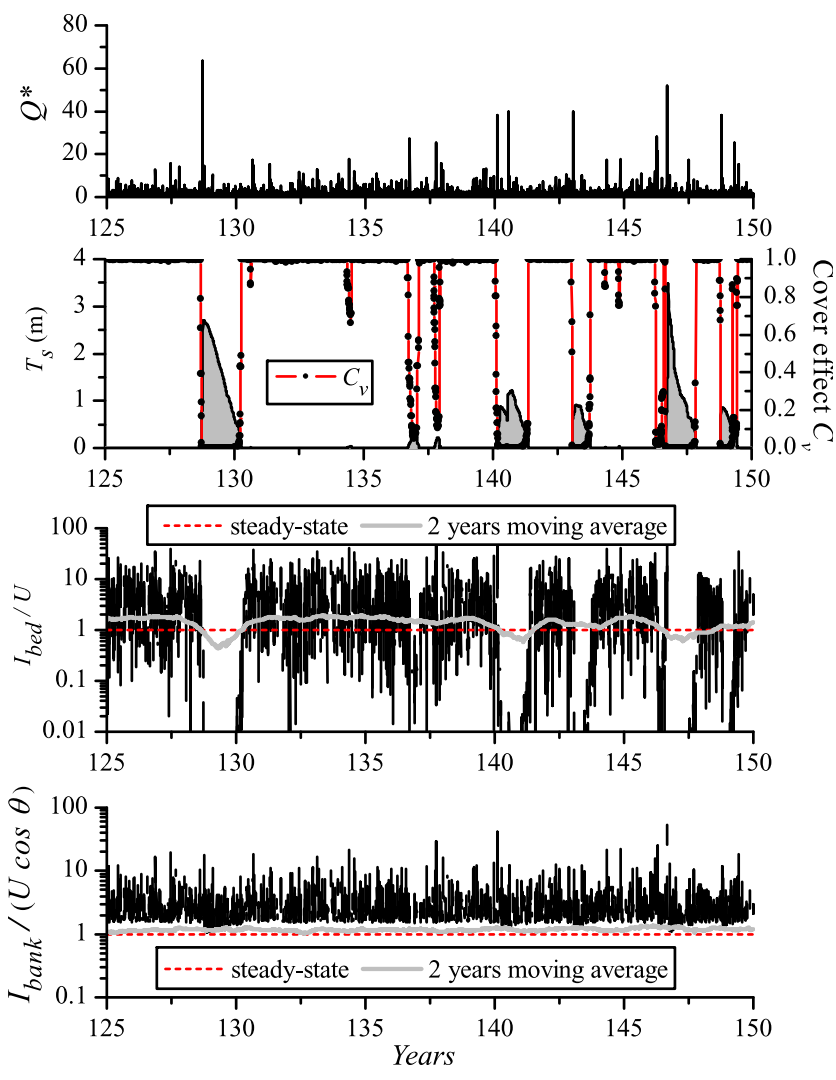

Figure 7. Temporal evolution of discharge, cover, and incision rates at daily time scales for $m=2$ at steady state. Large discharges deposit sediment that is progressively removed at time scales of months to years by lower discharges that are systematically net eroding (Figure 6). Note that the channel is rarely in partial cover effect configuration, but either on/off with respect to bed incision.

the imposed sediment supply rate $\bar{Q}_{s}$ is now increased to a value larger than $\bar{Q}_{t}^{*}$ (all other boundary conditions remaining equal), the channel will evolve toward a new steady state condition in which its mean sediment transport capacity $\bar{Q}_{t}$ is greater or equal to $\bar{Q}_{s}$ [Whipple and Tucker, 2002]. This example highlights, the possible feedback between $\bar{Q}_{s}$ and $\bar{Q}_{t}$, which first needs to be assessed in order to evaluate its consequences on the relationship $\bar{C}_{v}=f\left(\bar{Q}_{s} / \bar{Q}_{t}\right)$. It also illustrates a typical hybrid channel in which the steady state configuration depends on the supply of sediment $\bar{Q}_{s}$. In that case, the reference transport capacity $\bar{Q}_{t}^{*}$ can be used as a benchmark to determine whether detachment, transport capacity, or a combination of both is controlling the channel steady state configuration. According to the definitions that I suggest (section 2.1), one can define the three main possible channel configuration at steady state as a function of the relationships between $\bar{Q}_{s}, \bar{Q}_{t}$ and $\bar{Q}_{t}{ }^{*}$ :

(i) $\bar{Q}_{s} \leq \bar{Q}_{t}=\bar{Q}_{t}^{*}$, detachment-limited channels

(ii) $\bar{Q}_{t}^{*}<\bar{Q}_{s}<\bar{Q}_{t}$, hybrid channels

(ii) $\bar{Q}_{t}^{*}<\bar{Q}_{t}=\bar{Q}_{s}$, transport-capacity limited channels

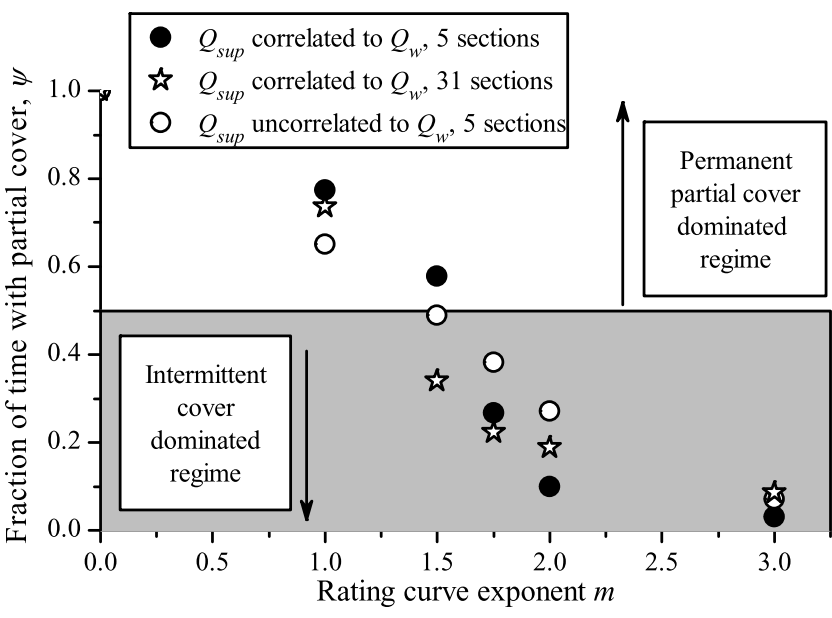

Figure 8. Impact of the nonlinearity of the sediment supply/discharge law, the length of the modeled reach, and the correlation between sediment supply and discharge on the dominant cover regime $(k=1, U=1 \mathrm{~mm} / \mathrm{yr})$. Standard deviation of $\psi$ is typically 0.2 . When the supply of sediment is perfectly correlated to discharge and for a model consisting of five cross sections, a rapid transition occurs around $m$ $\sim$ 1.5-1.6. This transition occurs for slightly lower $m$ for a model of 31 sections. When the supply of sediment obeys the same pdf, but is completely uncorrelated to discharge, the transition between the two regimes is more continuous. Note that this transition is likely to decrease with discharge variability (see Figure 9).

In practice, $\bar{Q}_{t}^{*}$ is evaluated for a given set of parameters and boundary conditions by running an identical model with $\bar{Q}_{s}=0$. In that case $\bar{Q}_{t}^{*}=\bar{Q}_{t}$.

[45] In the following, I do not detail how the bedrock channel geometry (width and slope) responds to variation of $\bar{Q}_{s}$, as this deserves in itself a separate study. But it is important to note that any steady state configuration in which $\bar{Q}_{t}>\bar{Q}_{t}{ }^{*}$, implies a change in bedrock channel slope

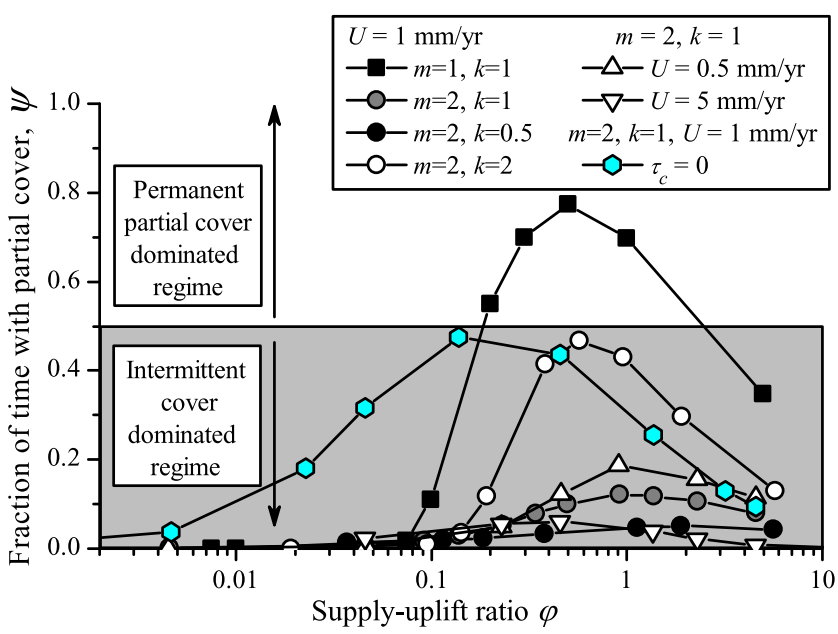

Figure 9. Impact of sediment supply, discharge variability, uplift rate, and threshold on the dominant regime of cover dynamics at steady state. 


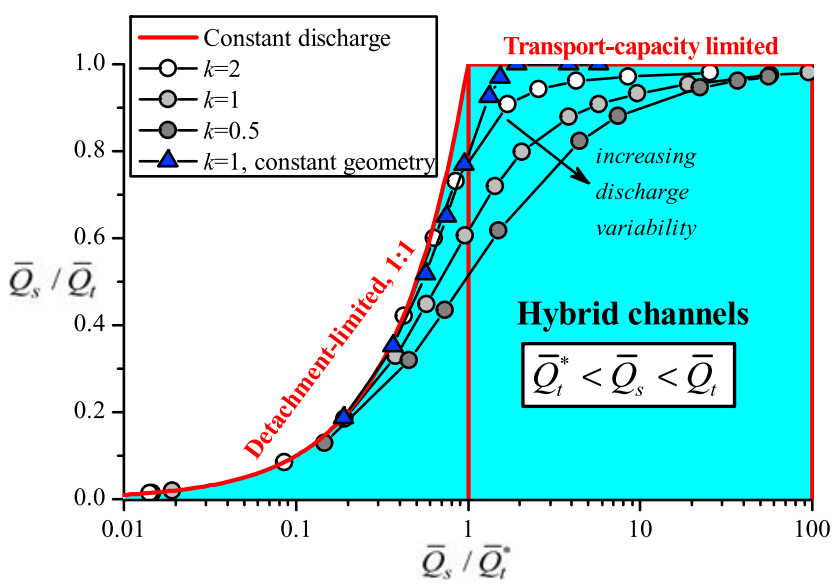

Figure 10. Variation of the under capacity degree $\bar{Q}_{s} / \bar{Q}_{t}$ as a function of the sediment supply rate $\bar{Q}_{s}$ normalized by the reference transport capacity $\bar{Q}_{t}^{*}$. Simulation parameters are $m=2, U=1 \mathrm{~mm} / \mathrm{yr}$, static cover expressed as a function of sediment thickness using equation (13). This diagram illustrates three possible steady state channel configurations: detachment limited, transport capacity limited, and hybrid. Natural channels (with discharge variability) are rarely detachment limited or transport capacity limited, but rather in a hybrid regime. Constant discharge models (i.e., effective discharge models) are either detachment limited or transport capacity limited. The data points corresponding to constant geometry are obtained by fixing bedrock channel width and slope at their value when $\bar{Q}_{s}=0$, and only allowing alluvial slope to vary because of sediment thickness fluctuations (see details in text).

and width in response to the increased sediment supply rate. This change is simply lumped into the cover effect law.

\subsection{Steady State Channel Configuration and Feedbacks Between $\overline{\boldsymbol{Q}}_{t}$ and $\overline{\boldsymbol{Q}}_{\boldsymbol{s}}$}

[46] Figure 10 presents the evolution of the under capacity degree $\left(\bar{Q}_{s} / \bar{Q}_{t}\right)$ as a function of the normalized sediment supply rate $\bar{Q}_{s} / \bar{Q}_{t}{ }^{*}$ for three values of discharge variability $(k=0.5,1$ and 2). Numerical model results for constant discharge are also included. They correspond to the asymptotic behavior of the variable discharge model for $k=+\infty$. Data points correspond to steady state configurations of the channel obtained for an uplift rate of $1 \mathrm{~mm} / \mathrm{yr}$ and increasing $\bar{Q}_{s}$. Figure 10 allows one to discriminate between the three types of channel models: the detachment-limited channel configuration corresponds to the curve $y=x$, i.e., $\bar{Q}_{t}=\bar{Q}_{t}{ }^{*}$. The transport capacity-limited channels occur for $\bar{Q}_{s} \bar{Q}_{t}=1$. Any point below these two curves implies that $\bar{Q}_{t}^{*}<\bar{Q}_{s}<$ $\bar{Q}_{t}$. In that case, the channel configuration has been altered to accommodate the increased sediment supply but not set such that $\bar{Q}_{s} / \bar{Q}_{t}=1$ : these are hybrid channels.

[47] A constant discharge model predicts only detachment-limited or transport capacity-limited channels depending on $\bar{Q}_{s} / \bar{Q}_{t}{ }^{*}$. This simply comes from the definition of the cover effect as a function of sediment thickness (equation (13)): when $\bar{Q}_{s}<\bar{Q}_{t}^{*}$, no sediment is deposited, and the incision efficiency and channel geometry are not altered. When $\bar{Q}_{s}>\bar{Q}_{t}{ }^{*}$, sediment starts to deposit on the bed, and incision efficiency is reduced. In that case, steady state conditions can only be reached if $\bar{Q}_{t}=\bar{Q}_{s}$, allowing the mean sediment thickness to be steady. Hence, the channel is transport capacity-limited, and cover effect increases with $\bar{Q}_{s}$. Discharge variability profoundly alters this by increasing the transport capacity of the channel for an otherwise identical rate of sediment supply when $\bar{Q}_{s} / \bar{Q}_{t}{ }^{*}>0.1$. This effect may originate from two causes: first, as explained before, bedrock channel geometry will evolve, if necessary, to reach a configuration in which $\bar{Q}_{s}<\bar{Q}_{t}$. This is expected to be important when $\bar{Q}_{s} / \bar{Q}_{t}^{*}>1$. Second, discharge and sediment supply stochasticity triggers temporary sediment deposition on the bed that increases the slope of the alluvial cover with respect to the bedrock slope. Over the long term, this will statistically increase $\bar{Q}_{t}$ above its reference value $\bar{Q}_{t}{ }^{*}$, even if the bedrock channel geometry has not been altered. Hence, this is a second positive feedback between $\bar{Q}_{s}$ and $\bar{Q}_{t}$ that I call the "stochasticity-driven feedback" to distinguish it from the channel geometry feedback.

[48] To test the relative importance of these two feedbacks on the relationship between $\bar{Q}_{t}$ and $\bar{Q}_{s}$, I ran a set of simulations in which the geometry of the bedrock channel was kept constant (width and bedrock slope), equal to the steady state geometry when $\bar{Q}_{s}=0$. Thus, only the stochasticity-driven feedback can operate. The model was run for 10,000 years without uplift rate and for various sediment supply rates (for $m=2$ and $k=1$ ). Results averaged over 10,000 years are shown in Figure 10. As expected, for $\bar{Q}_{s} \bar{Q}_{t}{ }^{*}$ greater than about $0.4, \bar{Q}_{t}$ is increased compared to $\bar{Q}_{t}{ }^{*}$. Because channel geometry cannot evolve, the channel reaches a transport capacity-limited regime at $\bar{Q}_{s} \bar{Q}_{t} * \sim 2$, where it then behaves simply as an alluvial channel. Comparison of the results with and without constant geometry for otherwise identical parameters (Figure 10) shows that the stochasticity driven feedback has an equal or smaller contribution than the channel geometry feedback in the deviation from the constant discharge predictions. For instance, at $\bar{Q}_{s} \bar{Q}_{t}{ }^{*}=1$, the stochasticity-driven feedback accounts for about $25 \%$ of under capacity $\bar{Q}_{s} / \bar{Q}_{t}$ reduction, while the channel geometry feedback further reduce this by another $25 \%$. For $\bar{Q}_{s} / \bar{Q}_{t}{ }^{*}$ larger than about two, the channel geometry feedback dominates the channel response at steady state. In that case, the numerical model predicts that transport capacity-limited conditions are never reached at steady state. It is important to note however, that for $\bar{Q}_{s} / \bar{Q}_{t}{ }^{*}>30-40$, the width/depth ratio of the steady state channels become increasingly large $(>150)$ such that the assumption of similar channel and valley width does not hold anymore, and model predictions may be biased. However, given the asymptotic behavior of the channel toward transport capacity-limited conditions, the detailed functional relationship does not exactly matter as $\bar{Q}_{s} / \bar{Q}_{t}$ is already larger than 0.9 .

[49] In Figure 10, the increased discharge variability leads to further departure from the constant discharge model. This is due to the increased frequency of large events: channel geometry must adapt not to transport the sediment supplied during intermediate frequent event (as for low discharge variability), but to transport the sediment deposited during the large events in order to decrease the fraction of time during which it is covered. Hence they tend to be configured into a lower under capacity degree $\bar{Q}_{s} / \bar{Q}_{t}$, for the same normalized sediment supply rate $\bar{Q}_{s} \bar{Q}_{t}{ }^{*}$. 


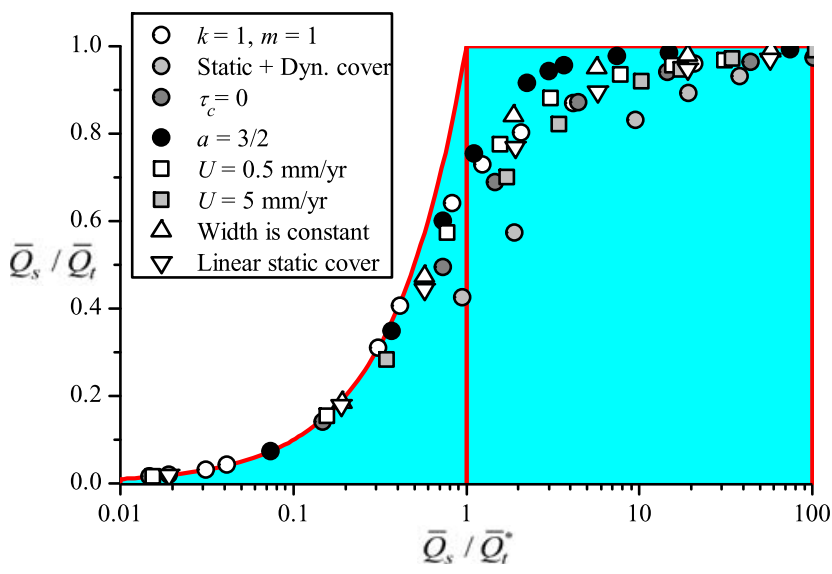

Figure 11. Effect of varying boundary conditions (discharge variability, uplift rate) and numerical model features (static and dynamic cover, variable width, linear static cover, incision exponent, critical shear stress) on the occurrence of hybrid channels in variable discharge simulations. If not specified in the legend, other parameters are $m=2, k=1$, $U=1 \mathrm{~mm} / \mathrm{yr}, a=1$, and exponential cover calculated as a function of sediment thickness.

[50] Figure 11 shows the sensitivity of the results to different features of the model (inclusion of dynamic cover, linear decline static cover, incision law exponent $a=3 / 2$ ) and boundary conditions (sediment supply nonlinearity, uplift rate). Whatever the features, the same trend as in Figure 10 is obtained. There are quantitative differences between all model features and boundary conditions, but it is not the objective of this paper to look into the details of these dependencies. Figure 11 rather demonstrate that the very existence of hybrid channels is not related to the intrinsic features of the model, but solely to the variable discharge and sediment supply, combined with a cover effect depending on sediment thickness. Hence, a freely variable width, the existence of a threshold of entrainment, the nonlinearity of the sediment supply, the exponential nature of the cover law, the linear relationship between incision rate and shear stress, and the uplift rate are not key factors governing the occurrence of hybrid channels. A notable difference is predicted for the combination of a static and dynamic cover effect which predicts a lower under capacity degree compared to other model description. It is explained by the additional reduction of incision by the dynamic cover model when no static alluvial cover is present. This tends to generate channels with larger transport capacity than when the dynamic cover effect is not factored in.

[51] Thus, the main conclusion of this part is that channels are expected to be most of the time hybrid channels, and detachment limited at very low sediment supply. Strictly speaking, steady state transport capacity-limited channels cannot exist, even though at very high sediment supply rate, the channel tends asymptotically toward a configuration in which $\bar{Q}_{s} \bar{Q}_{t} \sim 1$. This configuration illustrates the notion of "sediment load dominated channels" described by Johnson et al. [2009]. Note also, that this result is independent of the dominant cover regime (e.g., $k=1, m=1$ in Figure 11). I also emphasize the importance of two positive feedbacks between channel transport capacity and the sediment supply rate: (1) a stochasticity-driven feedback in which sediment deposits increase mean alluvial slope and consequently transport capacity and (2) a channel geometry driven feedback in which bedrock channel slope and width evolve such that $\bar{Q}_{t}>\bar{Q}_{s}$ at steady state. This later feedback dominates at normalized sediment supply rates $\bar{Q}_{s} / \bar{Q}_{t}{ }^{*}$ larger than 2 and time scales close to the response time of the channel (about 20,000 years in the present case). The stochasticity-driven feedback operates at much shorter time scales commensurate with the duration of stationary deposits in the channel.

\subsection{Long-Term Cover Effect Laws in the $\bar{Q}_{s} / \bar{Q}_{t}$ Framework}

[52] I now turn toward the long-term cover effect law. Given the existence of two feedbacks between $\bar{Q}_{t}$ and $\bar{Q}_{s}$, that are operative at different time scales and different ranges of sediment supply rate, I define two different cover effects to avoid confusion. First, the steady state cover effect $\bar{C}_{v}$ encompasses the two feedbacks and pertains to time scales that are larger than the response time of the channel. Second, the stochastic cover effect $\bar{C}_{s}$ only factors in the stochasticity driven feedback. It can be estimated using constant geometry simulations as in Figure 10. I address later in the discussion the time scales at which this cover effect operates.

[53] Figure 12 presents the long-term steady state cover effect $\bar{C}_{v}$ as a function of the under capacity degree $\bar{Q}_{s} / \bar{Q}_{t}$ for different discharge variability $(k=0.5,1,2)$, and the stochastic cover effect $\bar{C}_{s}$ for $k=1$. It corresponds to the same

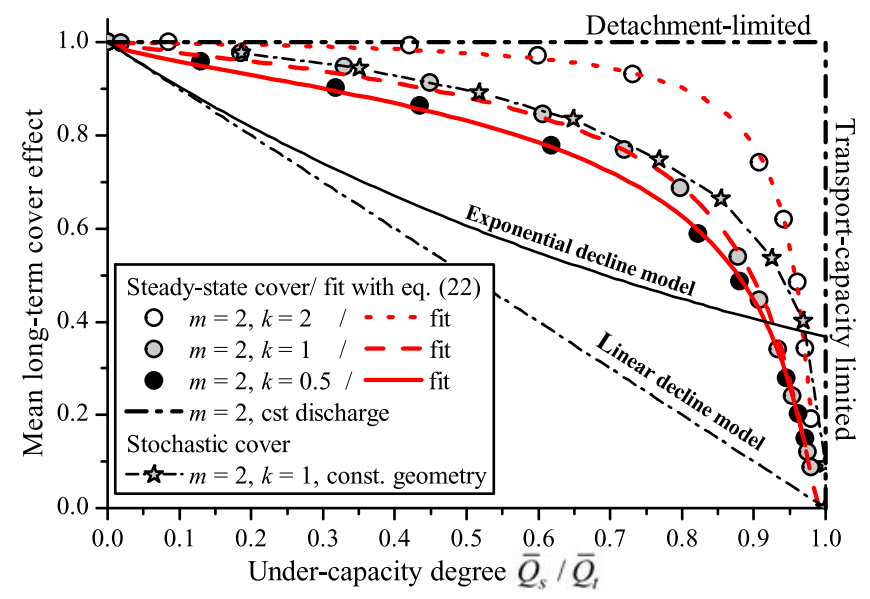

Figure 12. Long-term equivalent steady state cover effect $\bar{C}_{v}$ and stochastic cover effect $\bar{C}_{s}$ as a function of $\bar{Q}_{s} / \bar{Q}_{t}$ for different discharge variability. Theoretical linear [Sklar and Dietrich, 1998; Whipple and Tucker, 2002; Beaumont et al., 1992] and exponential decline model [Turowski et al., 2007] used in effective discharge models. Note that the exponential model has a free parameter that is set to 1 . This predicts significant incision for $\bar{Q}_{s} / \bar{Q}_{t}=1$. Parameters of the fit with equation (22) are $k=2, z=0.022, y=1.09, r^{2}=$ $0.99 ; k=1, z=0.125, y=0.79, r^{2}=0.98 ; k=0.5, z=0.189, y=$ $0.67, r^{2}=0.99$. The data points corresponding to stochastic cover effect geometry are obtained by fixing bedrock channel width and slope at their value when $\bar{Q}_{s}=0$, and only allowing alluvial slope to vary because of sediment thickness fluctuations (see details in text). 


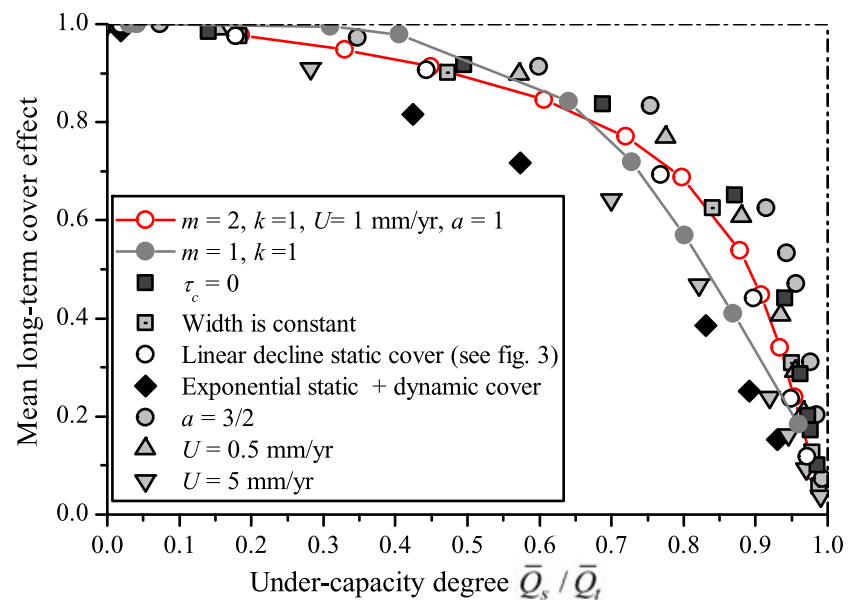

Figure 13. Long-term steady state cover effect as a function of the under capacity degree for various model parameters showing the consistent trend predicted whatever model features or boundary conditions. Note that linear decline static cover and exponential decline static cover predict almost the same results.

simulation results presented in Figure 10. Consistent with previous findings (Figure 10), the constant discharge simulations correspond either to detachment-limited channels $\left(\bar{Q}_{s}<\bar{Q}_{t}\right)$ with $\bar{C}_{v}=1$, or transport capacity-limited channels $\left(\bar{Q}_{s}=\bar{Q}_{t}\right)$. In the latter case, the cover effect is not related to the under capacity degree, but depends on the mean sediment thickness on the bed which increases with $\bar{Q}_{s}$. As in Figure 10, discharge variability induces an important shift from constant discharge predictions. For a given discharge variability, $\bar{C}_{v}$ decreases slightly with $\bar{Q}_{s} / \bar{Q}_{t}$ for low under capacity degree, and then very rapidly for $\bar{Q}_{s} \bar{Q}_{t}>0.6-0.7$. Comparing with Figure 10, this transition occurs for $\bar{Q}_{s} / \bar{Q}_{t}^{*} \sim$ $1-2$, where the channel geometry feedback starts to be dominant over the stochasticity-driven feedback. For larger under capacity degree, the variation of $\bar{C}_{v}$ with $\bar{Q}_{s} / \bar{Q}_{t}$ is thus dominated by changes in channel geometry. This explains the difference with the stochastic cover effect that does not factor in this feedback and predicts a smaller incision inhibition.

[54] Figure 12 shows that neither the steady nor the stochastic cover effects obey the linear or exponential decline cover models [Beaumont et al., 1992; Gasparini et al., 2006; Sklar and Dietrich, 1998; Tucker and Slingerland, 1994; Turowski et al., 2007; Whipple and Tucker, 2002] (equations (1) and (2)). The numerical model results predict (1) a much smaller inhibition of incision efficiency in average than theoretical models and (2) a much more nonlinear behavior. In particular, because of the channel geometry and stochastic feedback, there is a very strong sensitivity of incision reduction to $\bar{Q}_{s} / \bar{Q}_{t}$ close to transport capacity configuration that is not captured by the linear and exponential cover models. The impact of discharge and sediment supply variability is also obviously not captured.

[55] As in Figure 11, Figure 13 illustrates the sensitivity of the relationship $\bar{C}_{v}=f\left(\bar{Q}_{s} / \bar{Q}_{t}\right)$ to various features of the numerical model definition (incision laws, cover models, freely variable width) and boundary conditions (nonlinearity of discharge, uplift rate). It demonstrates that the general trend observed in Figure 12 is very consistent whatever the model description, and that the theoretical linear or exponential model cover cannot be predicted even by adding or removing complexity to the model. Obviously, adding a dynamical cover effect does tend to reduce incision efficiency compared to the case without dynamical cover, because incision reduction also occurs in the absence of static alluvial cover. Using the linear static cover model in place of the exponential has almost no effect on the longterm cover effect at steady state. This suggest that the detail of the functional relationship used to actually compute the static cover effect (Figure 3) does not translate into a fundamentally different steady state cover effect law.

[56] I thus conclude that the trend of the steady state cover effect law $\bar{C}_{v}=f\left(\bar{Q}_{s} / \bar{Q}_{t}\right)$ results from 3 elements mainly independent of the model formulation: (1) the long-term impact of alluvial thickness variability and the associated incision reduction, (2) the stochasticity driven feedback that is important at low sediment supply rates and arises because of the explicit calculation of alluvial cover thickness, and (3) the channel geometry feedback that is dominant at large sediment supply rates. The same conclusion applies for the stochastic cover effect $\bar{C}_{s}$ except that the channel geometry feedback is not operative. This permits reaching configurations in which $\bar{Q}_{s} / \bar{Q}_{t}=1$, and $\bar{C}_{s}=0$ (Figure 12).

[57] There is no simple functional relationship that fits correctly the relationship $\bar{C}_{v}=f\left(\bar{Q}_{s} / \bar{Q}_{t}\right)$ for the entire range of $\bar{Q}_{s} / \bar{Q}_{t}$. This is not surprising given the different feedback dominating at low and high under capacity degrees. I suggest an ad hoc model that is sufficiently general to fit a wide range of configurations:

$$
\bar{C}_{v}=\exp \left(-z\left(\frac{\bar{Q}_{s} / \bar{Q}_{t}}{1-\bar{Q}_{s} / \bar{Q}_{t}}\right)^{y}\right),
$$

where $z$ and $y$ are constant depending on boundary conditions and incision law parameters. As shown in Figure 12, the values of $z$ and $y$ vary with discharge variability. In particular, $y$, which is the measure of the degree of deviation from a pure exponential behavior $(y=1)$, decreases with discharge variability from 1.09 (for $k=2$ ) to 0.67 (for $k=$ 0.5 ). I did not try to systematically document the variation of $z$ and $y$ as they will depend on the choice of model formulation and boundary conditions (in particular discharge variability), such that no universal law can be defined.

\subsection{Long-Term Cover Effect Laws in the $\bar{Q}_{s} / \bar{Q}_{t}{ }^{*}$ Framework}

[58] Casting the cover effect in terms of the under capacity degree (equation (22)) has the drawback of lumping the feedbacks between $\bar{Q}_{t}$ and $\bar{Q}_{s}$ (Figures 10 and 11). In order to avoid this, I now study the two cover effects in the $\bar{Q}_{s} / \bar{Q}_{t}{ }^{*}$ framework. This is illustrated in Figure 14. The cover effect variations are now very different from Figure 12. For the steady state cover effect, the onset of a significant incision reduction occurs for a normalized sediment supply between 0.1 and 1 , consistent with the variation of sediment transport capacity documented in Figure 10. Then $\bar{C}_{v}$ decreases at a diminishing rate with $\bar{Q}_{s} / \bar{Q}_{t}^{*}$. No simple functional relationship (exponential or power law) was found to predict correctly the numerical results for the complete range of $\bar{Q}_{s} /$ $\bar{Q}_{t}{ }^{*}$. This is expected given the different feedback dominating the behavior at low and high sediment supply rates. 


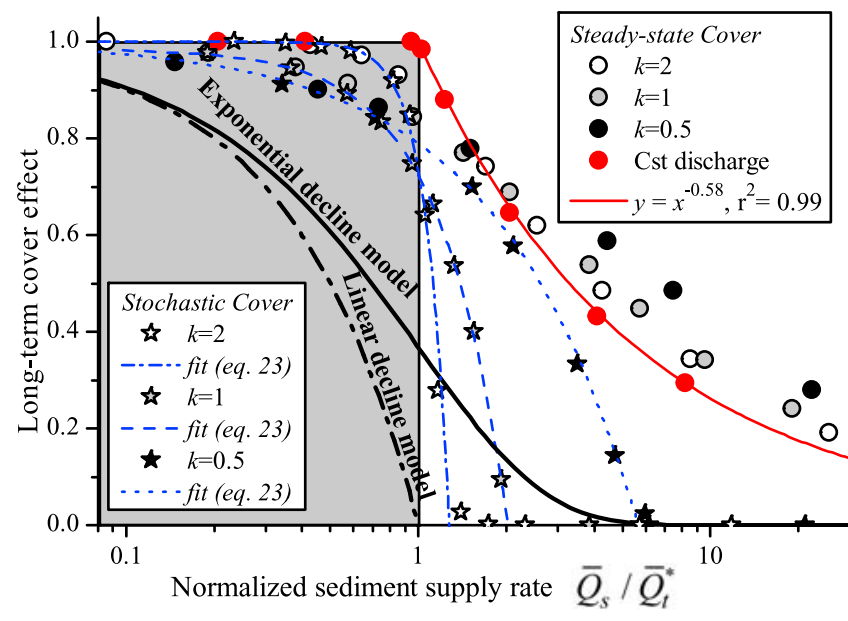

Figure 14. Steady state and stochastic cover effect as a function of the normalized sediment supply $\bar{Q}_{s} / \bar{Q}_{t}{ }^{*}$. Using equation (23) to fit the stochastic cover data gives the following relationships: for $k=2, y=1-0.26 x^{5.5}, r^{2}=0.99$, for $k=1, y=1-0.26 x^{1.82}, r^{2}=0.99$, for $k=0.5, y=1$ $0.21 x^{0.90}, r^{2}=0.99$.

The only exception is the constant discharge model for which $\bar{C}_{v}=1$ for $\bar{Q}_{s} / \bar{Q}_{t}^{*}<1$, and $\bar{C}_{v}=\left(\bar{Q}_{s} / \bar{Q}_{t}^{*}\right)^{-0.58}\left(r^{2}=0.99\right)$ for $\bar{Q}_{s} / \bar{Q}_{t}^{*}>1$. This latter trend seems to be the asymptotic tendency of all variable discharge simulations, suggesting that for large $\bar{Q}_{s} / \bar{Q}_{t}^{*}, \bar{C}_{v}$ decreases as a power law (Figure 14). Note that model predictions might be biased for $\bar{Q}_{s} / \bar{Q}_{t}{ }^{*}>$ $20-30$ as the predicted width/depth ratio is typically larger than 150 .

[59] The stochastic cover effect exhibits an evolution similar to the steady state cover for $\bar{Q}_{s} / \bar{Q}_{t}{ }^{*}$ smaller than about 1 , but decreases toward zero at a rate depending on discharge variability (Figure 14). Complete cover occurs for $\bar{Q}_{s} \bar{Q}_{t} * \sim 2$ for $k=1$, and $\bar{Q}_{s} \bar{Q}_{t}^{*} \sim 7$ for $k=0.5$. This highlights the strength of the stochasticity-driven feedback that permits incision for sediment supply rate several times larger than the reference transport capacity of the channel. Indeed, without this feedback (i.e., constant discharge) cover should be complete at or just above $\bar{Q}_{s} / \bar{Q}_{t}^{*}=1$. Interestingly, the stochastic cover effect obeys a well defined relationship in the $\bar{Q}_{s} / \bar{Q}_{t}^{*}$ framework (Figure 14):

$$
\bar{C}_{s}=1-k_{c}\left(\frac{\bar{Q}_{s}}{\bar{Q}_{t}^{*}}\right)^{\gamma},
$$

with $k_{c}$ slightly decreasing with discharge variability, and the exponent $\gamma$ decreasing very rapidly with discharge variability (from 6.82 at $k=2$ to 0.9 for $k=0.5$ ). It is also interesting to study the stochastic cover effect in terms of mean long-term alluvial thickness. Figure 15 shows that $\bar{C}_{s}$ decreases linearly with mean alluvial thickness (Figure 15), except for low discharge variability $(k=2)$ where the long-term stochastic cover effect is marginally different from the exponential static cover effect law (equation (13)). It is interesting to note that the short-term exponential static cover effect law is progressively replaced by an approximate linear decline relationship as discharge variability increases. It further strengthens the idea that the functional relationship (equation (23)) of the

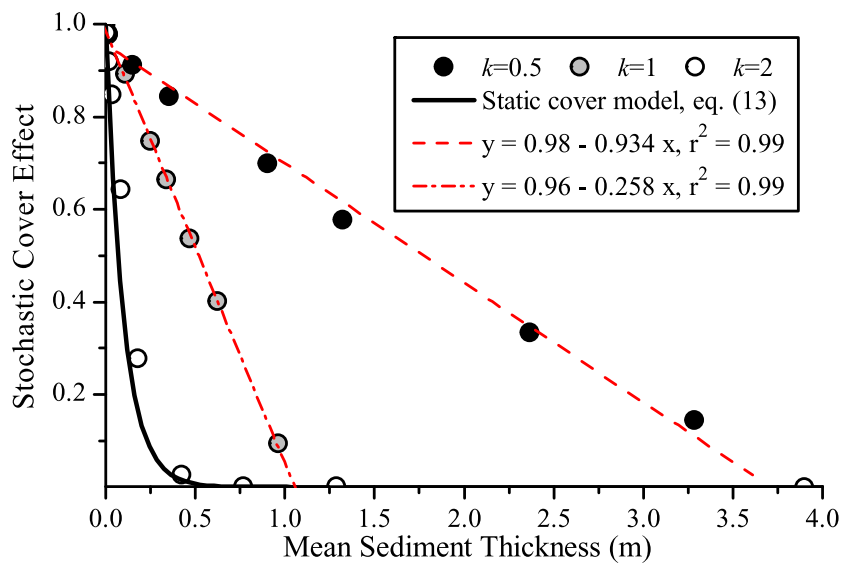

Figure 15. Relationships between stochastic cover effect and mean sediment thickness for different discharge variability. Each data point corresponds to the average values over 10,000 years obtained for a simulation with fixed bedrock channel geometry (i.e., slope can only vary because of alluvial deposits).

long-term stochastic cover effect is not strongly dependent on the formulation of the static cover effect at daily time scales (see also Figure 13). I also explored the additional role of a dynamic cover effect on the stochastic cover effect. I used an exponential decline formulation [Turowski et al., 2007], and a linear decline [Sklar and Dietrich, 2004] in two different sets of simulation in which the static cover was effective. Figure 16 shows that in both cases, equation (23) is still verified (exponential decline, $k_{c}=0.40, \gamma=1.29, \mathrm{r}^{2}=0.99$; linear decline, $k_{c}=0.45, \gamma=1.10, \mathrm{r}^{2}=0.99$ ). As expected the incision reduction is more pronounced because the dynamic cover effect is reducing incision for all discharges that transport sediment. However, even by factoring in an additional dynamic cover effect, the long-term stochastic cover effect is still very different from the theoretical linear and exponential cover models.

[60] I also ran a series of simulations using 31 sections rather than 5 , while the studied section remains the central one (only static cover is considered). The reason is that

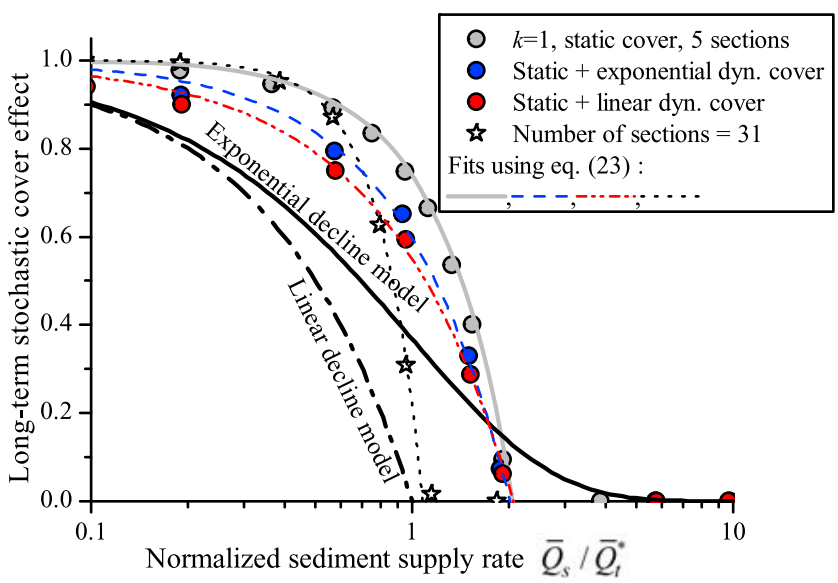

Figure 16. Sensitivity of the stochastic cover effect to dynamic cover effect and channel length (i.e., number of sections in the model). 
sediment transport being an inherently diffusive process [Metivier, 1999; Paola et al., 1992], its dynamics depend on the size of the system, and it will likely influence sediment thickness fluctuations [Benda and Dunne, 1997b]. Figure 16 shows that increasing the size of considered reach and the distance to the outlet by a factor of six does not change the functional relationship between $\bar{C}_{s}$ and $\bar{Q}_{s} \bar{Q}_{t}{ }^{*}$, but induces a more nonlinear cover reduction than with 5 sections $\left(k_{c}=\right.$ $\left.0.78, \gamma=3.20, r^{2}=0.99\right)$ despite similar boundary conditions and model features. The incision reduction is more important because the increased distance to the outlet limits the amplitude of slope variations, and thus reduces the strength of the stochasticity-driven feedback. On the other hand, the cover regime is even more dominated by intermittency (For the data on Figure 16, the maximum of $\psi$ is 0.15 for $n=31$, and $\psi=0.31$ for $n=5$, see also Figure 8).

\section{Discussion}

[61] I have introduced the SSTRIM code, a new numerical model of bedrock channel incision and sediment transport driven by a stochastic variation of discharge and sediment supply at daily time scales. This model has been used to study the dynamics of sediment cover variation at short time scales and the integrated effect on long-term incision efficiency in a steady state configuration. In the following, I discuss the possible consequences of simplifying assumptions in the numerical model. Then I discuss the likely prevailing regime of cover dynamics in nature and the occurrence of mixed bedrock channels in nature. Finally, I seek to improve on the modeling strategies used to factor in the cover effect in theoretical and numerical channel evolution studies.

\subsection{Effects of Simplifying Assumptions in the Numerical Model}

[62] I have demonstrated that the detailed features of the model do not change the results to the point where the predicted long-term cover effect law $\bar{C}_{v}=f\left(\bar{Q}_{s} / \bar{Q}_{t}\right)$ can be reconciled with the linear or exponential decline cover models (Figures 12 and 13). Obviously, this affirmation is bound to the range of parameters used, and to the processes described in the model.

[63] An important simplification pertains to the assumption that water flow always occupies the entire channel bed especially when width/depth ratio are large (i.e., larger than 100-150). In that case, the potential error is greatest at low flows where the channel could actually be narrower and deeper, and entrain part of the sediment in transport, while the model predicts no transport. Yet, it is unlikely that this effect will change the very existence of the intermittent cover regime or the long-term cover effect, as it is mainly governed by the dynamics at intermediate and very high discharges, for which width/depth ratios are smaller, than the width/depth ratio determined for the mean annual discharge (for $k=1, m=2$ and $\varphi=4.55$, the average width/ depth ratio at mean discharge is $W / D=371$, but the width/ depth ratio for a discharge 10 times larger is $W / D=61$ ).

[64] It is difficult to assess the effect of the trapezoidal cross section and the assumption of constant bank angle on model results. The equivalent at-a-station hydraulic geometry of a trapezoidal channel resembles asymptotically the average behavior of Taiwan rivers. However, the assumption of constant bank angle is possibly incorrect as the cross-sectional shape of bedrock channels seems dependent on the average sediment concentration in the river [Turowski et al., 2008a]. Yet, given that mean sediment thickness is primarily dependent on the base width of the channel $W_{b}$, and less on the bank angle, I do not expect that the inclusion of bank angle dependent on sediment concentration would change my conclusions.

[65] Neglecting the positive effect of impacting bed load or suspended particles on incision efficiency (the tools effect) [Lamb et al., 2008; Sklar and Dietrich, 2001] can potentially be important for steady state model predictions at low sediment supply rates. In particular, in the strict case where incision cannot occur without transported sediment, model predictions will obviously be very different. Note however, that this does not affect the stochastic cover model results as it deals solely with the reduction of incision by cover and is independent of incision processes and rates. A complete upscaled incision model should incorporate a tools effect, but I have centered the topic of this study on cover effects only.

[66] Perhaps the most important simplification pertains to the treatment of subreach complexity, including lateral variations in sediment transport, roughness effects, bed form dynamics and multiple grain sizes. Experiments of sediment-driven channel incision into cohesive material show that the lateral variations in bed roughness and alluvial cover drive important lateral variation in the pattern of incision at a scale smaller than channel width [Finnegan et al., 2007; Johnson and Whipple, 2007]. These variations ultimately alter bed incision efficiency and are supposed to be captured by the simple cover effect law expressed as a function of mean cover thickness, and potentially via the dynamic cover effects. The choice of an exponential function is quite speculative, but in the other hand, model results show that the overall dynamics is not very sensitive to the choice of the elementary static cover effect law (exponential versus linear decline), and the inclusion of a dynamic cover effect. However, the model does not account for possible variations in transport efficiency between bare bedrock and alluvial configurations. Chatanantavet and Parker [2008] demonstrated experimentally that alluvial cover dynamics strongly depends on roughness variations related to the state of the bed, such that it is difficult to define a simple consistent model of the percent of exposed bedrock surface as a function of $Q_{s} / Q_{t}$. Similarly, recent field analysis of bedrock channel incision under different degrees of mantling by coarse material [Johnson et al., 2009] suggests that variations of bed roughness may play an important role in governing the reduction of incision by sediment transport over the long term. A central question is to determine whether the combination of bed roughness, multiple grain sizes, bed form dynamics and other complexity related to sediment transport make bare bedrock channels more or less efficient in transporting sediment than alluvial, or partly covered channels [Yager et al., 2007]. In terms of long-term cover effect law, one can posit that, if alluvial channels transport sediment more efficiently (by smoothing the bedrock channel profile for instance), then a positive feedback occurs in which $\bar{Q}_{t}$ increases with $\bar{Q}_{s}$ because of the increased fraction of time during which the channel tends to be covered by sediment. 
This would, on top of the stochastic cover effect, further increases the nonlinearity of the long-term cover effect law and the range of $\bar{Q}_{s} / \bar{Q}_{t}$ for which incision is barely reduced. The opposite would occur if bare bedrock channels transport sediment more efficiently than alluvial channels. This requires further work and additional constraints on the transport efficiency of mountain rivers.

\subsection{Intermittent Versus Permanent Partial Cover Dynamics in Nature}

[67] The two end-member regimes of cover dynamics exhibited by the numerical model are intuitively expected, and have been postulated by previous theoretical studies [Howard, 1998; Whipple and Tucker, 2002]. The intermittent nature of bedrock incision and cover, has also been documented in the field [Hartshorn et al., 2002; Turowski et al., 2008b] (Figure 1). The modeling results improve our understanding of the key parameters controlling the occurrence of one regime or the other, and can guide our analysis of bedrock rivers by quantifying how representative are presentday conditions compared to long-term dynamics. Before I actually discuss these two points, I first try to assess whether the basic treatment of discharge and sediment supply stochasticity in the model captures the necessary elements of the complex stochastic forcing of mountain bedrock rivers.

[68] Discharge events (and the supply of sediment) in nature are temporally correlated at daily to monthly time scales: large floods typically occur over a couple of days and seasonality alters the probability of extreme events (droughts or floods). In this study, I have neglected this correlation, but it is likely not critical as the cover dynamics regime is more dependent on the nonlinearity between sediment supply rate and discharge than on the actual sequence of events. In particular, I showed that even with a completely uncorrelated supply of sediment with respect to discharge, the two regimes of bed cover are still predicted.

[69] The other critical aspect controlling the dominance of intermittent versus continuous partial cover regime is the linearity of the transport capacity with discharge (Figure 6) during flooding events. This linearity comes from the $3 / 2$ exponent on bed shear stress of the "traditional" transport capacity laws (equation (14)) [Fernandez-Luque and Van Beek, 1976; Meyer-Peter and Müller, 1948], and the dependency of shear stress on discharge as $Q^{1 / 3}$ and width on discharge as $Q^{1 / 2}$ (see Howard [1994] for a derivation). However, the predictive capacity of bed load transport equations is rather poor for mountain rivers in particular [Barry et al., 2004; Gomez and Church, 1989; Rickenmann, 2001], and this is still an active area of research. For instance, recent work suggests that the dependency of bed load transport capacity on shear stress could be more nonlinear at high transport rates with $Q_{s} \sim \tau^{5 / 2}$ [Recking et al., 2008]. In that case, the transport capacity would scale with discharge as $Q^{1.44}$ reducing the range of nonlinearity of sediment supply over which the intermittent cover regime is dominant.

[70] Finally, the full range of grain sizes has been reduced to a single representative one that I have assumed to be $D_{50}$. It is of no importance for discharges where the channel is completely covered, but it could be important for intermediate discharges where the channel could transport $D_{50}$, but not $D_{90}$, for instance. The expected result would be to have events with incision inhibition by cover (complete or partial) more evenly distributed over all the discharges, and a tendency to be more in the permanent partial cover regime. As discussed above, roughness variations may also alter the relative dominance of the intermittent versus permanent partial cover regimes in a way that is difficult to predict because it not only affects the local dynamics, but also the upstream storage and release of sediment.

[71] Factoring in the limitations in numerical modeling discussed previously, I find that cover intermittency is favored by discharge variability, strong nonlinearity between sediment supply and discharge (i.e., $m>1.5$, Figure 8 ), and the presence of a threshold of transport (even small). All these conditions being typical of mountain rivers, I suggest that the intermittent cover regime is possibly the dominant mode of cover dynamics in these settings. This is consistent with field examples in Taiwan exhibiting rapid variations in the volume of sediment stored in channels (Figure 1) [Hartshorn et al., 2002; Turowski et al., 2008b]. Rivers are potentially in the permanent partial cover regime, for very low sediment supply or linear relationship between sediment supply and discharge $(m=1)$. This later case could be found in locations where upstream sediment supply is almost permanently transport limited or not influenced by landsliding. Note that the degree of intermittency of the cover effect is likely going to vary in channel network as the dominance of local supply, upstream supply and channel transport capacity is systematically varying and lead to different degrees of alluvial thickness variability and probability of aggradation [Benda and Dunne, 1997b]. This requires a more comprehensive study of the dynamics of stochastic sediment supply and transport in drainage network.

[72] An important prediction of the model is that bedrock channels with a typical alluvial cover of several meters could still be actively incising over the long term (Figures 4 and 7). This is particularly consistent with the ubiquitous presence of alluvial deposits in mountain rivers [Howard, 1998; Lavé and Avouac, 2001; Turowski et al., 2008a, 2008b], sometimes quite thick (Figure 1). In these environments, the predicted variability of sediment cover precludes the use of present-day measurement of the extent of sediment deposits on the bed to estimate the cover effect over the long term. Indeed, even in the continuous partial cover regime, it seems very unlikely that the present-day spatial distribution of alluvial cover could be representative of the long-term cover effect (Figure 5). The model predictions also support a recent theoretical work proposed by Stark et al. [2009], in which channel stream power is supposed to dissipate through successive phases of alluvial cover degradation and bare bedrock incision.

[73] Finally, in the intermittent cover regime, the model predicts that extreme events are not the "dominant" discharge or "effective" discharge in bedrock channels, as most of the vertical incision occurs during intermediate discharge events. However, large events are important because of the systematic covering effect that they tend to trigger and the concurrent lateral erosion that they drive [Hartshorn et al., 2002; Turowski et al., 2008b].

\subsection{Channel Regimes at Steady State}

[74] The model demonstrates that discharge and sediment supply variability smear out the dichotomy of channel con- 


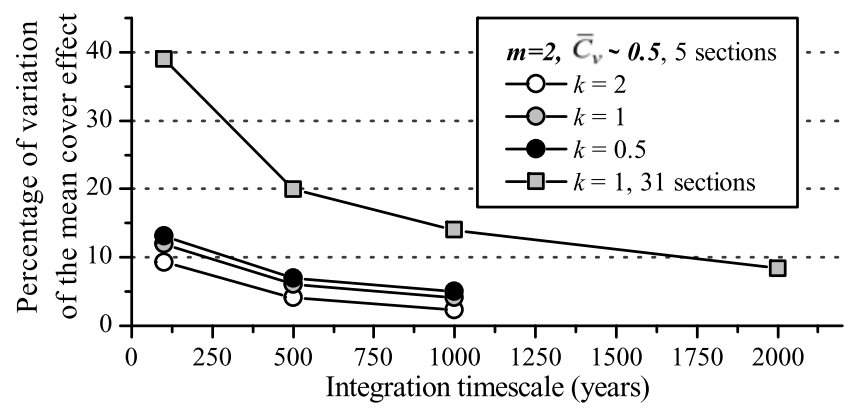

Figure 17. Relationship between the variation of the mean cover effect during a 10,000 year simulation with constant geometry as a function of the integration time scale over which daily values are averaged.

figuration regimes predicted by a constant discharge model: channels are never strictly transport capacity limited (or transport limited as it has been previously termed) [Whipple and Tucker, 2002], and only detachment limited at very low sediment supply rate [Howard and Kerby, 1983; Howard, 1994; Whipple and Tucker, 1999]. For a wide range of sediment supply rates, they are hybrid channels, because their channel geometry is altered by the supply of sediment, compared to the case without sediment. Within the context of this numerical study, the reference transport capacity $\bar{Q}_{t}{ }^{*}$ permits discrimination between these configurations in a simple way. Yet the concept of reference transport capacity cannot readily be applied to real cases as one cannot simply calculate the equivalent theoretical steady state geometry of a channel in which no incision reduction would occur. Note also that $\bar{Q}_{t}^{*}$ cannot be defined if sediment transport has a positive effect on incision (tools effect).

[75] The model illustrates the dynamics of channels whose steady state configuration is very close to complete transport capacity and whose dynamics will likely resemble those of transport capacity alluvial channels [Whipple and Tucker, 2002] or sediment load-dominated channels [Johnson et al., 2009]. This may explain the occurrence of diffusive-like behavior during transient response to baselevel fall [Loget et al., 2006; Valla et al., 2010]. Within the same modeling framework, knickpoint migration typical of detachment-limited channels [Whipple and Tucker, 1999] is easily reproduced by the model for low rates of sediment supply. These results are consistent with models where $\bar{Q}_{s} /$ $\bar{Q}_{t}<1$ at steady state [Gasparini et al., 2006; Sklar and Dietrich, 2006; Turowski et al., 2007].

\subsection{Upscaled Cover Effect Laws}

[76] Because of history effects, there cannot be a direct relationship between static cover and the under capacity degree at short time scales [Turowski et al., 2007]. I demonstrated that such a relationship emerges over the long term, as intuitively expected by many authors [Beaumont et al., 1992; Sklar and Dietrich, 1998]. However, the resulting long-term cover effects laws are very different from previous, mostly empirical, models [Beaumont et al., 1992; Sklar and Dietrich, 1998; Turowski et al., 2007] and experimental studies [Chatanantavet and Parker, 2008]. Moreover, these laws are not unique, and there is not a single incision reduction for a given under capacity ratio: incision reduction increases with discharge variability and the inclusion of dynamic cover effect. Most importantly, because cover dynamics is likely dominated by the intermittent regime, details of the cover model or incision law at daily time scales have a secondary effect on the long-term cover effect compared to the variability of sediment and water supply. This result suggests that the focus of future research on bedrock river dynamics should not only encompass detailed process studies [e.g., Hancock et al., 1998; Hartshorn et al., 2002; Lamb et al., 2008; Sklar and Dietrich, 2004; Turowski, 2009], but also factor in the complexity arising from stochastic input, storage and transport of sediment in bedrock rivers [Benda and Dunne, 1997a, 1997b; Hovius et al., 2000; Lancaster, 2008; Stark et al., 2009; Stark and Guzzetti, 2009], including extreme events like river damming [Korup et al., 2006; Ouimet et al., 2007].

[77] The long-term cover effect laws predicted by the model depend on two important feedbacks between $\bar{Q}_{t}$ and $\bar{Q}_{s}$ that tend to reduce the incision inhibition at any given $\bar{Q}_{s}$. Two types of long-term cover effect laws can thus be defined: first, a steady state cover effect law in which channel geometry variations maintain the channel in the under capacity regime. It is valid at time scales commensurate with the response time of the channel. In the numerical simulations above, this is typically $20,000 \pm 2000$ years whatever the discharge variability and sediment supply rate. At shorter time scales, I define the stochastic cover effect law resulting from the fluctuations of alluvial cover thickness on the bed. This intermittent deposition tends to increase the mean transport capacity compared to the case without sediment deposition. This latter cover effect law is valid at steady state or during transient dynamics. When cast in terms of the reference sediment supply discharge $\bar{Q}_{s} / \bar{Q}_{t}{ }^{*}$, the stochastic cover effect is a simple power law decline (equation (23)). Contrary to the strict reference transport capacity used in the steady state cover effect, $\bar{Q}_{t}^{*}$ in equation (23) corresponds to the mean transport capacity of the bedrock channel section without any sediment deposits. It can thus be theoretically estimated in any river provided that the discharge statistics, the critical shear stress of sediment transport and the flow resistance coefficient are known. The power law exponent in equation (23) strongly varies with sediment and discharge variability, and is also dependent on channel size. I did not attempt to explore the full range of controls on this functional relationship, as the objective of this study was mainly to demonstrate the qualitative importance of short-term stochastic dynamics on long-term incision efficiency reduction in bedrock channels. However, it could theoretically be used in numerical models assuming an effective discharge model [Crosby et al., 2007; Gasparini et al., 2006; Whipple and Tucker, 2002] provided that a minimum time scale of integration is respected. Figure 17 permits estimation of this minimum integration time scale. It shows the variability of the cover effect averaged over different time scales. The mean long-term cover variability decreases with integration time and with decreasing discharge variability. Arbitrarily setting at $10 \%$ of variability the limit at which the mean cover effect is representative of the mean long-term cover given by equation (23), I found that the minimum time scale of integration varies between $\sim 100$ years for $k=2$, and $\sim 300$ years for $k=0.5$, for 5 sections. For 30 sections the time scale is of the order of 1700 years. Hence it is difficult to anticipate the 
exact value of the time scale at which the stochastic cover effect law (equation (23)) is an average model of the shortterm variability, but it can be quite short compared to channel response time.

[78] These results show that the long-term cover effect that could be inferred from the analysis of present-day channels should be done with caution. At present, the model lacks the inclusion of the tools effect, and cannot fully resolve the expected variation of incision efficiency with sediment supply, in particular at low sediment supply rates [Sklar and Dietrich, 2004]. However, it is important to note that a stronger nonlinearity between incision efficiency and under capacity degree is expected near transport capacitylimited configuration than previously envisioned. This is relevant for studies that try to assess the cover and tools theory with field data [Cowie et al., 2008; Johnson et al., 2009], as slight variations in the present-day configuration of channels, and the corresponding transport capacity, may result in important variations in incision reduction.

\section{Conclusion}

[79] Following the work of Stark [2006], I have introduced a new numerical model (code STRIMM) that resolves sediment transport, bedrock incision and channel geometry evolution at daily time scales, and can be run for thousands of years. It incorporates (1) a combination of transport threshold and daily stochastic variations in water discharge and sediment supply, (2) a freely evolving channel width and slope according to bed and bank incision, and (3) an explicit treatment of alluvial thickness variations and corresponding bed incision reduction. Additional components can be added, including tools effects [Sklar and Dietrich, 2001], grain size variations along stream [Attal and Lave, 2006] or different modes of stochastic sediment supply [Benda and Dunne, 1997a; Fuller et al., 2003]. I use a rating curve-like model to link sediment supply rate to daily discharge, and shows that it reproduces the pdf of sediment volume mobilized from large landslides provided that a specific combination of discharge variability parameter $k$ and rating curve exponent $m$ is chosen. Model results predict the existence of two asymptotic cover dynamics regime: permanent partial cover regime and intermittent cover regime. In this latter case, the cover effect operates over the long term by modulating the proportion of time where the channel is fully or not covered. These results are largely independent of the intricate details of incision laws or model features such as freely variable width or dynamic cover effects [Turowski et al., 2007]. Intermittent cover regime is favored by: large discharge variability, strong nonlinearity between sediment supply and discharge (in terms or rating curve equivalent $m>$ 1.5), and the presence of a threshold of entrainment (even small). All these conditions being typical of mountain rivers, I suggest that intermittent cover regime is probably the dominant mode of cover dynamics in rapidly eroding areas where landslide supply dominates. This is consistent with field observations in the Liwu River of Taiwan [Hartshorn et al., 2002; Turowski et al., 2008b]. However, a more comprehensive study of the along-stream variations of alluvial cover dynamics resulting from stochastic sediment supply, temporary storage and transport [Benda and Dunne, $1997 \mathrm{~b}$ ] is required to evaluate, for instance, if low-order streams tends to systematically operate in the intermittent cover regime and high-order streams to be more in the permanent partial cover regime. Future work should also focus on the relative importance of the pdf of sediment supply and the pdf of water discharge to distinguish their respective effect and the potential consequences of roughness variations and multiple grain sizes.

[80] Model results also demonstrate that considering daily stochasticity leads to steady state channels that are mainly hybrid channels [Whipple and Tucker, 2002]: they are below capacity over the long term, but rarely strictly detachment limited as their slope is predicted to be always a function of sediment supply (even if small) on top of local controls (uplift rate, sediment transport threshold, ...). Depending on the rate of sediment supply with respect to the reference transport capacity of the channel at steady state (that is the transport capacity when $\bar{Q}_{s}=0$ ), the channel configuration varies from near detachment-limited conditions to near transport capacity-limited conditions in a continuous way. Strictly speaking, transport capacity-limited and detachmentlimited models cannot be used to model steady state geometric properties [Lague et al., 2003, 2005; Loget et al., 2006; Whipple and Tucker, 2002].

[81] Over the long term the daily variation of alluvial thickness and corresponding incision reduction results in a cover effect that can be defined as a function of the ratio between long-term sediment supply and sediment transport capacity. Depending on the integration time scale considered, one can distinguish a stochastic cover effect in which channel geometry is considered about constant, and a steady state cover effect commensurate with the response time of the channel. Both resulting cover effects are very different from the proposed theoretical linear or exponential decay models [Beaumont et al., 1992; Sklar and Dietrich, 1998; Turowski et al., 2007; Whipple and Tucker, 2002], and are mostly dependent on the variability of discharge and sediment supply, and the possible role of the dynamic cover effect. Compared to previous models, they predict very large variations of incision reduction as the channel approaches a transport capacity-limited regime and a weak sensitivity at low under capacity degree. The stochastic cover effect decreases as a power law if expressed as a function of the ratio between sediment supply rate and the reference transport capacity. This law effectively integrates short-term variations of alluvial thickness and can theoretically be used in numerical models using a constant discharge model [Crosby et al., 2007; Gasparini et al., 2006; Whipple and Tucker, 2002]. However, given the unknown sensitivity of the model parameters to discharge variability, channel length, and model formulation, the best approach to tackle the study of bedrock channel evolution remains to explicitly model the alluvial cover thickness and its short-term variability.

[82] This study is a first step toward a complete upscaling of short-term bedrock channel dynamics necessary to determine whether simple incision laws relating vertical incision rate to sediment supply rate, discharge distribution characteristics and channel slope could be defined, and used in large-scale numerical models of landscape evolution [e. g., Braun and Sambridge, 1997; Davy and Lague, 2009]. For this the tools effect [Lamb et al., 2008; Sklar and Dietrich, 2004] should be included, and the effectiveness of the dynamic cover effect and its functional relationship 
should be evaluated. Overall, as advocated with simpler incision laws [Lague et al., 2005; Snyder et al., 2003; Tucker and Bras, 2000], these results point to the fundamental role of stochasticity on long-term dynamics that is often neglected in constant discharge models [Gasparini et al., 2006; Sklar and Dietrich, 2006; Whipple and Tucker, 2002] and cannot be simply factored into effective discharge models [Lague et al., 2005].

[83] Acknowledgments. Helpful discussion with J. Turowski, P. Davy, J. Lavé, and L. Sklar were greatly appreciated. Detailed comments by Joel Johnson, the Associate Editor, the Editor, and two anonymous reviewers have helped improving the paper. This work has been funded by a CNRS/INSU/RELIEFS project "Dynamique des réseaux hydrographiques" and supported by the French Agence Nationale de la Recherche (ANR) under grant ANR-05-blan-0273.

\section{References}

Attal, M., and J. Lave (2006), Changes of bedload characteristics along the Marsyandi river (Central Nepal): Implications for understanding hillslope sediment supply, sediment load evolution along fluvial networks, and denudation in active orogenic belts, in Tectonics, Climate and Landscape Evolution, edited by S. D. Willett et al., Spec. Pap. Geol. Soc. Am., 398, 143-171, doi:10.1130/2006.2398(09).

Barry, J. J., J. M. Buffington, and J. G. King (2004), A general power equation for predicting bed load transport rates in gravel bed rivers, Water Resour. Res., 40, W10401, doi:10.1029/2004WR003190.

Beaumont, C., P. Fullsack, and J. Hamilton (1992), Erosional control of active compressional orogens, in Thrust Tectonics, edited by K. R. McClay, pp. 1-18, Chapman and Hall, New York.

Benda, L. (1990), The influence of debris flows on channels and valley floors in the Oregon Coast Range, USA, Earth Surf. Processes Landforms, 15, 457-466, doi:10.1002/esp.3290150508.

Benda, L., and T. Dunne (1997a), Stochastic forcing of sediment supply to channel networks from landsliding and debris flow, Water Resour. Res., 33, 2849-2863, doi:10.1029/97WR02388.

Benda, L., and T. Dunne (1997b), Stochastic forcing of sediment routing and storage in channel networks, Water Resour. Res., 33, 2865-2880, doi:10.1029/97WR02387.

Braun, J., and M. Sambridge (1997), Modelling landscape evolution on geological time scales: A new method based on irregular spatial discretization, Basin Res., 9, 27-52, doi:10.1046/j.1365-2117.1997.00030.x.

Brocard, G. Y., and P. van der Beek (2006), Influence of incision rate, rock strength and bedload supply on bedrock river gradients and valley-flat widths: Field-based evidence and calibrations from western Alpine rivers (SE France), in Tectonics, Climate and Landscape Evolution, edited by S. D. Willett et al., Spec. Pap. Geol. Soc. Am., 398, 101-126, doi:10.1130/2006.2398(07)

Cantelli, A., M. Wong, G. Parker, and C. Paola (2007), Numerical model linking bed and bank evolution of incisional channel created by dam removal, Water Resour. Res., 43, W07436, doi:10.1029/2006WR005621.

Chatanantavet, P., and G. Parker (2008), Experimental study of bedrock channel alluviation under varied sediment supply and hydraulic conditions, Water Resour. Res., 44, W12446, doi:10.1029/2007WR006581.

Cowie, P. A., A. C. Whittaker, M. Attal, G. Roberts, G. E. Tucker, and A. Ganas (2008), New constraints on sediment-flux-dependent river incision: Implications for extracting tectonic signals from river profiles, Geology, 36, 535-538, doi:10.1130/G24681A.1.

Crosby, B. T., K. X. Whipple, N. M. Gasparini, and C. Wobus (2007), Formation of fluvial hanging valleys: Theory and simulation, J. Geophys. Res., 112, F03S10, doi:10.1029/2006JF000566.

Dadson, S. (2004), Erosion of an active mountain belt, Ph.D. thesis, Univ. of Cambridge, Cambridge, U. K.

Dadson, S., et al. (2003), Links between erosion, runoff variability and seismiciy in the Taiwan orogen, Nature, 426, 648-651, doi:10.1038/ nature 02150 .

Dadson, S., et al. (2004), Earthquake-triggered increase in sediment delivery from an active mountain belt, Geology, 32, 733-736, doi:10.1130/ G20639.1.

Davy, P., and A. Crave (2000), Upscaling local-scale transport processes in large-scale relief dynamics, Phys. Chem. Earth Part A, 25(6-7), 533541, doi:10.1016/S1464-1895(00)00082-X.

Davy, P., and D. Lague (2009), Fluvial erosion/transport equation of landscape evolution models revisited, J. Geophys. Res., 114, F03007, doi:10.1029/2008JF001146.
Duvall, A., E. Kirby, and D. W. Burbank (2004), Tectonic and lithologic controls on bedrock channel profiles and processes in coastal California, J. Geophys. Res., 109, F03002, doi:10.1029/2003JF000086.

Fernandez-Luque, R., and R. Van Beek (1976), Erosion and transport of bed-load sediment, J. Hydraul. Res., 14, 127-144.

Finnegan, N. J., L. S. Sklar, and T. K. Fuller (2007), Interplay of sediment supply, river incision, and channel morphology revealed by the transient evolution of an experimental bedrock channel, J. Geophys. Res., 112, F03S11, doi:10.1029/2006JF000569.

Flintham, T. P., and P. A. Carling (1988), The prediction of mean bed and wall boundary shear in uniform and compositely rough channels, in International Conference on River Regime, 18-20 May, 1988, edited by W. R. White, pp. 267-287, John Wiley, New York.

Fuller, C. W., S. D. Willett, N. Hovius, and R. L. Slingerland (2003), Erosion rates for Taiwan mountain basins: New determinations from suspended sediment records and a stochastic model of their temporal variation, J. Geol., 111, 71-87, doi:10.1086/344665.

Gasparini, N. M., R. L. Bras, and K. X. Whipple (2006), Numerical modeling of non-steady-state river profile evolution using a sediment-fluxdependent incision model, in Tectonics, Climate and Landscape Evolution, edited by S. D. Willett et al., Spec. Pap. Geol. Soc. Am., 398, 127-141, doi:10.1130/2006.2398(08).

Gomez, B., and M. Church (1989), An assessment of bedload sediment transport formulae for gravel-bed rivers, Water Resour. Res., 25, 1161-1186, doi:10.1029/WR025i006p01161.

Hancock, G. S., and R. S. Anderson (2002), Numerical modeling of fluvial strath-terrace formation in response to oscillating climate, Geol. Soc. Am. Bull., 114, 1131-1142, doi:10.1130/0016-7606(2002).

Hancock, G. S., R. S. Anderson, and K. X. Whipple (1998), Beyond power: Bedrock river incision process and form, in Rivers Over Rock: Fluvial Processes in Bedrock Channels, Geophys. Monogr. Ser., vol. 107, edited by K. J. Tinkler and E. E. Wohl, pp. 35-60, AGU, Washington, D. C. Hartshorn, K., N. Hovius, W. B. Dade, and R. L. Slingerland (2002), Climate-driven bedrock incision in an active mountain belt, Science, 297, 2036-2038, doi:10.1126/science.1075078.

Hovius, N., C. P. Stark, and P. A. Allen (1997), Sediment flux from a mountain belt derived by landslide mapping, Geology, 25, 231-234, doi:10.1130/0091-7613(1997)025<0231:SFFAMB >2.3.CO;2.

Hovius, N., C. P. Stark, C. Hao-Tsu, and L. Jiun-Chuan (2000), Supply and removal of sediment in a landslide-dominated mountain belt: Central Range, Taiwan, J. Geol., 108, 73-89, doi:10.1086/314387.

Howard, A. D. (1994), A detachment-limited model of drainage basin evolution, Water Resour. Res., 30, 2261-2285, doi:10.1029/94WR00757.

Howard, A. D. (1998), Long profile development of bedrock channels: Interaction of weathering, mass wasting, bed erosion and sediment transport, in Rivers Over Rock: Fluvial Processes in Bedrock Channels, Geophys. Monogr. Ser., vol. 107, edited by K. J. Tinkler and E. E. Wohl, pp. 297-319, AGU, Washington, D. C.

Howard, A. D., and G. Kerby (1983), Channel changes in badlands, Geol. Soc. Am. Bull., 94, 739-752, doi:10.1130/0016-7606(1983)94<739: CCIB $>2.0 . \mathrm{CO} ; 2$.

Johnson, J. P., and K. X. Whipple (2007), Feedbacks between erosion and sediment transport in experimental bedrock channels, Earth Surf. Processes Landforms, 32, 1048-1062, doi:10.1002/esp.1471.

Johnson, J. P. L., K. X. Whipple, L. S. Sklar, and T. C. Hanks (2009), Transport slopes, sediment cover, and bedrock channel incision in the Henry Mountains, Utah, J. Geophys. Res., 114, F02014, doi:10.1029/ 2007JF000862.

Knight, D. W. (1981), Boundary shear in smooth and rough channels, $J$. Hydraul. Div. Am. Soc. Civ. Eng., 107(7), 839-851.

Knight, D. W., J. D. Demetrious, and M. E. Hamed (1984), Boundary shear in smooth rectangular channels, J. Hydraul. Eng. 110(4), 405-422.

Knight, D. W., M. Omran, and X. Tang (2007), Modeling depth-averaged velocity and boundary shear in trapezoidal channels with secondary flows, J. Hydraul. Eng., 133(1), 39-47, doi:10.1061/(ASCE)0733-9429(2007) 133:1(39).

Korup, O., A. L. Strom, and J. T. Weidinger (2006), Fluvial response to large rock-slope failures: Examples from the Himalayas, the Tien Shan, and the Southern Alps in New Zealand, Geomorphology, 78, 3-21, doi:10.1016/j.geomorph.2006.01.020.

Lague, D., A. Crave, and P. Davy (2003), Laboratory experiments simulating the geomorphic response to tectonic uplift, J. Geophys. Res., 108(B1), 2008, doi:10.1029/2002JB001785.

Lague, D., N. Hovius, and P. Davy (2005), Discharge, discharge variability, and the bedrock channel profile, J. Geophys. Res., 110, F04006, doi:10.1029/2004JF000259.

Lamb, M. P., W. E. Dietrich, and L. S. Sklar (2008), A model for fluvial bedrock incision by impacting suspended and bed load sediment, $J$. Geophys. Res., 113, F03025, doi:10.1029/2007JF000915. 
Lancaster, S. T. (2008), Evolution of sediment accomodation space in steady state bedrock-incising valleys subject to episodic aggradation, J. Geophys. Res., 113, F04002, doi:10.1029/2007JF000938.

Lancaster, S. T., and G. E. Grant (2006), Debris dams and the relief of headwater streams, Geomorphology, 82, 84-97, doi:10.1016/j. geomorph.2005.08.020

Lavé, J., and J. P. Avouac (2001), Fluvial incision and tectonic uplift across the Himalayas of central Nepal, J. Geophys. Res., 106, 26,561-26,591.

Lenzi, M. A., L. Mao, and F. Comiti (2004), Magnitude-frequency analysis of bed load data in an Alpine boulder bed stream, Water Resour. Res., 40, W07201, doi:10.1029/2003WR002961.

Loget, N., P. Davy, and J. Van den Driessche (2006), Mesoscale fluvial erosion parameters deduced from modeling the Mediterranean sea leve drop during the Messinian (late Miocene), J. Geophys. Res., 111, F03005, doi:10.1029/2005JF000387.

Malamud, B. D., D. L. Turcotte, F. Guzzetti, and P. Reichenbach (2004), Landslide inventories and their statistical properties, Earth Surf. Processes Landforms, 29, 687-711, doi:10.1002/esp.1064.

Metivier, F. (1999), Diffusive-like buffering and saturation of large rivers, Phys. Rev. E, 60, 5827-5832, doi:10.1103/PhysRevE.60.5827.

Meyer-Peter, E., and R. Müller (1948), Formulas for bed-load transport, paper presented at 2nd Congress of IAHR, Stockholm, Sweden.

Molnar, P., R. S. Anderson, G. Kier, and J. Rose (2006), Relationships among probability distributions of stream discharges in floods, climate, bed load transport, and river incision, J. Geophys. Res., 111, F02001, doi:10.1029/2005JF000310.

Ouimet, W. B., K. X. Whipple, L. H. Royden, Z. Sun, and Z. Chen (2007), The influence of large landslides on river incision in a transient landscape: Eastern margin of the Tibetan Plateau (Sichuan, China), Geol. Soc. Am. Bull., 119, 1462-1476, doi:10.1130/B26136.1.

Paola, C., and V. R. Voller (2005), A generalized Exner equation for sediment mass balance, J. Geophys. Res., 110, F04014, doi:10.1029/ 2004JF000274.

Paola, C., P. L. Heller, and C. L. Angevine (1992), The large-scale dynamics of grain-size variation in alluvial basins: 1. Theory, Basin Res., 4, 73-90.

Recking, A., P. Frey, A. Paquier, P. Belleudy, and J. Y. Champagne (2008), Feedback between bed load transport and flow resistance in gravel and cobble bed rivers, Water Resour. Res., 44, W05412, doi:10.1029/ 2007WR006219.

Rickenmann, D. (2001), Comparison of bed load transport in torrents and gravel bed streams, Water Resour. Res., 37, 3295-3305, doi:10.1029/ 2001WR000319.

Schuerch, P., A. L. Densmore, B. W. McArdell, and P. Molnar (2006), The influence of landsliding on sediment supply and channel change in a steep mountain catchment, Geomorphology, 78, 222-235, doi:10.1016/ j.geomorph.2006.01.025.

Sklar, L., and W. E. Dietrich (1998), River longitudinal profiles and bedrock incision models: Stream power and the influence of sediment supply, in Rivers Over Rock: Fluvial Processes in Bedrock Channels, Geophys. Monogr. Ser., vol. 107, edited by K. J. Tinkler and E. E. Wohl, pp. 237-260, AGU, Washington, D. C.

Sklar, L. S., and W. E. Dietrich (2001), Sediment and rock strength controls on river incision into bedrock, Geology, 29, 1087-1090, doi:10.1130/ 0091-7613(2001)029<1087:SARSCO >2.0.CO;2.

Sklar, L. S., and W. E. Dietrich (2004), A mechanistic model for river incision into bedrock by saltating bed load, Water Resour. Res., 40, W06301, doi:10.1029/2003WR002496.

Sklar, L. S., and W. E. Dietrich (2006), The role of sediment in controlling steady-state bedrock channel slope: Implications of the saltationabrasion incision model, Geomorphology, 82, 58-83, doi:10.1016/j. geomorph.2005.08.019

Snyder, N. P., K. X. Whipple, G. E. Tucker, and D. J. Merritts (2003), Importance of a stochastic distribution of floods and erosion thresholds in the bedrock river incision problem, J. Geophys. Res., 108(B2), 2117, doi:10.1029/2001JB001655.

Stark, C. P. (2006), A self-regulating model of bedrock river channel geometry, Geophys. Res. Lett., 33, L04402, doi:10.1029/2005GL023193.

Stark, C. P., and F. Guzzetti (2009), Landslide rupture and the probability distribution of mobilized debris volumes, J. Geophys. Res., 114, F00A02, doi:10.1029/2008JF001008.

Stark, C. P., and N. Hovius (2001), The characterization of landslide size distributions, Geophys. Res. Lett., 28(6), 1091-1094, doi:10.1029/ 2000 GL008527.
Stark, C. P., E. Foufoula-Georgiou, and V. Ganti (2009), A nonlocal theory of sediment buffering and bedrock channel evolution, J. Geophys. Res., 114, F01029, doi:10.1029/2008JF000981.

Tomkin, J. H., M. T. Brandon, F. J. Pazzaglia, J. R. Barbour, and S. D. Willett (2003), Quantitative testing of bedrock incision models for the Clearwater River, NW Washington State, J. Geophys. Res., 108(B6), 2308, doi:10.1029/2001JB000862.

Tucker, G. E., and R. L. Bras (2000), A stochastic approach to modeling the role of rainfall variability in drainage basin evolution, Water Resour. Res., 36, 1953-1964, doi:10.1029/2000WR900065.

Tucker, G. E., and R. L. Slingerland (1994), Erosional dynamics, flexural isostasy, and long-lived escarpments: A numerical modeling study, J. Geophys. Res., 99, 12,229-12,243.

Turowski, J. M. (2009), Stochastic modeling of the cover effect and bedrock erosion, Water Resour. Res., 45, W03422, doi:10.1029/ 2008WR007262.

Turowski, J., and D. Rickenmann (2008), Tools and cover effects in bedload transport observations in the Pitzbach, Austria, Earth Surf. Processes Landforms, 34, 26-37, doi:10.1002/esp.1686.

Turowski, J., D. Lague, A. Crave, and N. Hovius (2006), Experimental channel response to tectonic uplift, J. Geophys. Res., 111, F03008, doi:10.1029/2005JF000306.

Turowski, J., D. Lague, and N. Hovius (2007), The cover effect in bedrock abrasion: A new derivation and its implications for the modeling of bedrock channel morphology, J. Geophys. Res., 112, F04006, doi:10.1029/ 2006JF000697.

Turowski, J., N. Hovius, A. Wilson, and M. J. Horng (2008a), Hydraulic geometry, river sediment and the definition of bedrock channels, Geomorphology, 99, 26-38, doi:10.1016/j.geomorph.2007.10.001.

Turowski, J. M., N. Hovius, M.-L. Hsieh, D. Lague, and M.-C. Chen (2008b), Distribution of erosion across bedrock channels, Earth Surf. Processes Landforms, 33, 353-363, doi:10.1002/esp.1559.

Turowski, J. M., D. Lague, and N. Hovius (2009), Response of bedrock channel width to tectonic forcing: Insights from a numerical model, theoretical considerations, and comparison with field data, J. Geophys. Res., 114, F03016, doi:10.1029/2008JF001133.

Valla, P., P. van der Beek, and D. Lague (2010), Fluvial incision into bedrock: Insights from morphometric analysis and numerical modeling of gorges incising glacial hanging valleys (Western Alps, France), J. Geophys. Res., 115, F02010, doi:10.1029/2009JF001079.

van der Beek, P., and P. Bishop (2003), Cenozoic river profile development in the Upper Lachlan catchment (SE Australia) as a test of quantitative fluvial incision models, J. Geophys. Res., 108(B6), 2309, doi:10.1029/ 2002JB002125.

Whipple, K. X., and G. E. Tucker (1999), Dynamics of the stream-power river incision model: Implications for height limits of mountain ranges, landscape response timescales, and research needs, J. Geophys. Res., 104, 17,661-17,674.

Whipple, K. X., and G. E. Tucker (2002), Implications of sediment-fluxdependent river incision models for landscape evolution, J. Geophys. Res., 107(B2), 2039, doi:10.1029/2000JB000044.

Whipple, K. X., G. S. Hancock, and R. S. Anderson (2000), River incision into bedrock: Mechanics and relative efficacy of plucking, abrasion, and cavitation, Geol. Soc. Am. Bull., 112, 490-503, doi:10.1130/0016-7606 (2000) $112<490:$ RIIBMA $>2.0$. CO;2.

Whittaker, A. C., P. Cowie, M. Attal, G. E. Tucker, and G. P. Roberts (2007), Bedrock channel adjustment to tectonic forcing: Implications for predicting river incision rates, Geology, 35, 103-106, doi:10.1130/ G23106A.1.

Wobus, C. W., G. E. Tucker, and R. S. Anderson (2006), Self-formed bedrock channels, Geophys. Res. Lett., 33, L18408, doi:10.1029/ 2006GL027182.

Yager, E. M., J. W. Kirchner, and W. E. Dietrich (2007), Calculating bed load transport in steep boulder bed channels, Water Resour. Res., 43, W07418, doi:10.1029/2006WR005432.

D. Lague, Géosciences Rennes, Université Rennes 1, UMR 6118 , Campus de Beaulieu, F-35042 Rennes, CEDEX, France. (Dimitri. Lague@univ-rennes1.fr) 